\title{
Inflammatory Response in the CNS: Friend or Foe?
}

\author{
Marta Sochocka $^{1} \cdot$ Breno Satler Diniz ${ }^{2} \cdot$ Jerzy Leszek $^{3}$ \\ Received: 30 August 2016/Accepted: 9 November 2016/Published online: 26 November 2016 \\ (C) The Author(s) 2016. This article is published with open access at Springerlink.com
}

\begin{abstract}
Inflammatory reactions could be both beneficial and detrimental to the brain, depending on strengths of their activation in various stages of neurodegeneration. Mild activation of microglia and astrocytes usually reveals neuroprotective effects and ameliorates early symptoms of neurodegeneration; for instance, released cytokines help maintain synaptic plasticity and modulate neuronal excitability, and stimulated toll-like receptors (TLRs) promote neurogenesis and neurite outgrowth. However, strong activation of glial cells gives rise to cytokine overexpression/dysregulation, which accelerates neurodegeneration. Altered mutual regulation of p53 protein, a major tumor suppressor, and NF- $\mathrm{kB}$, the major regulator of inflammation, seems to be crucial for the shift from beneficial to detrimental effects of neuroinflammatory reactions in neurodegeneration. Therapeutic intervention in the $\mathrm{p} 53-\mathrm{NF}-\mathrm{KB}$ axis and modulation of TLR activity are future challenges to cope with neurodegeneration.
\end{abstract}

Keywords Neuroinflammation - Immune response in the CNS $\cdot$ Microglia activation $\cdot$ Cytokines $\cdot$ miRNA .

Neurodegeneration

Jerzy Leszek

jerzy.leszek@umed.wroc.pl

1 Hirszfeld Institute of Immunology and Experimental Therapy, Polish Academy of Sciences, Wroclaw, Poland

2 Department of Psychiatry and Behavioral Sciences, and The Consortium on Aging, University of Texas Health Science Center at Houston, Houston, TX, USA

3 Department of Psychiatry, Wroclaw Medical University, Wybrzeże L. Pasteura 10, 50-367 Wroclaw, Poland

\section{Introduction}

In the central nervous system (CNS), degenerative processes are characterized by morphological, anatomical, and functional changes that lead to early, chronic, and progressive neuronal loss. Chronic neurodegenerative diseases are defined as hereditary, sporadic, and protein misfolding diseases, which are usually characterized also by the decline of cognitive functions, particularly learning and memory. These include Alzheimer's disease (AD) and other dementias, transmissible spongiform encephalopathies (TSEs), amyotrophic lateral sclerosis (ALS), Parkinson's disease (PD), Huntington's disease (HD), and prion diseases. The causes associated with neuronal degeneration remain poorly understood. Generally known risk factors for most neurodegenerative diseases are genetic polymorphisms and advanced age. The prevailing hypothesis is that the protein aggregates or seeds ( $\alpha$-synuclein, amyloid beta $(A \beta)$, lipofuscin, tau protein) trigger a cascade of events leading to neurodegeneration and neuronal apoptosis [1-3]. Several other mechanisms may be involved in the pathogenesis of neurodegenerative disorders, including chronic inflammation, vascular factors, oxidative stress, and reduced availability of trophic factors in the brain.

Regulation of immuno-inflammatory control is one of the relevant processes involved in the pathogenesis of neurodegenerative disorders. Innate and adaptive immune response in the brain are tightly controlled in relation with the periphery. Immune activation in the CNS always involves microglia and astrocytes, which, in non-pathological conditions, contributes in the regulation of homeostasis of the brain tissue. Endothelia cells and perivascular macrophages are also important to the interpretation and propagation of inflammatory signals within the CNS [4]. In the CNS, microglia always scan the microenvironment by producing factors that influence adjacent astrocytes and neurons, particularly in response to infection or 
neuronal cell injury. This leads to the activation of an inflammatory response that further engages a transient, self-limiting response through the immune system and initiates tissue repair. Under pathological conditions, when the normal resolution mechanisms failed, there is an abnormal activation and production of inflammatory factors, leading to chronic neuroinflammatory state and progression of neurodegenerative changes.

Chronic neuroinflammation is observed at relatively early stages of neurodegenerative disease. The mentioned neurodegenerative factors impact on glial function by overactivation of both microglia and astrocytes triggering production and releasing large amounts of pro-inflammatory cytokines and reactive oxygen and nitrogen species (ROS, RNS). Chronic activation of microglia is linked to the degradation of protein, the dysfunction of mitochondria, and the defects of axonal transport and apoptosis, which have a detrimental effect on neuronal function and lead to cell death. Furthermore, neuroinflammation results in the subsequent infiltration of immune cells from the periphery to the CNS across the blood brain barrier (BBB), which accelerates neuroinflammation and neurodegeneration [5].

In this review, we aim to address the role of microglia, astrocytes, and immune response in the CNS in the development of neurodegenerative disorders. The review will present the "two faces" of neuroinflammation, which can result in the restoration of brain homeostasis as well as initiation or/and acceleration of neurodegenerative processes.

\section{Inflammation, Inflammaging, and Neuroinflammation}

Inflammation is a complex biological response of the body to cell and tissue damages caused by chemical (acids, alkali), physical (ionizing radiation, magnetic field, ultrasonic waves), and biological factors (viruses, bacteria, fungi, exotoxins, and endotoxins) [6]. The type and range of inflammatory response depend on the type and intensity of the irritant. In addition, the tissue and organ resistance is also important. The potency of the irritant and the time of its impact on tissue determine the type of inflammatory state, acute or chronic. Inflammation can be beneficial as an acute, transient immune response to harmful conditions such as tissue injury or an invading pathogen. The proper inflammatory reactions facilitate the repair, turnover, and adaptation of tissues. In addition, moderate inflammatory reaction leads to the inhibition of bleeding resulting from trauma and removal of necrotic tissues, exotoxins, and endotoxins with exudation. Inflammation is a multistage response. The reactions of the mobility of cells, humoral response, i.e., activation of inflammatory mediators present locally and in body fluids, and the hemostatic response are engaged. The proper inflammatory response is self-limiting and characterized by an advantage of processes of restoring homeostasis over the destructive processes [7]. However, acute inflammatory response to pathogen-associated molecular patterns (PAMPs) may be impaired during aging, leading to increased susceptibility to infection. If the activity of the stimulating factor is persistent in time and the mechanisms of the proper development of inflammation are dysregulated, the body still receives a signal of health hazard and switches from the acute to a chronic inflammatory state $[7,8]$. As a result, this causes an imbalance in the immune system, thereby the inflammatory markers remain permanently and generally at low grade. Chronic inflammation consecutively leads to the tissue degeneration and development of autoimmune or circulatory system diseases, arthritis, cancers, and CNS disorders [9].

Aging is a complex process that depends on many environmental factors and genetic and epigenetic events occurring in the different types of cells and tissues throughout life. Moreover, the aging process is a chronic oxidative and inflammatory stress, leading to damage of cell components, including proteins, lipids, and DNA, and contributing to the agerelated decline of physiological functions [10]. "Inflammaging," referred to as systemic, chronic inflammation, by Franceschi and Salvioli and colleagues [11, 12], is also the dominant feature of body aging and most, if not all, age-related diseases [8]. Many epidemiological studies confirm that inflammaging is a strong risk factor of various diseases, including AD, and death in the elderly. Inflammaging is connected with the increased level of inflammatory markers such as C-reactive protein (CRP) or interleukin-6 (IL-6) and also associated with many age-related changes, e.g., in the body composition, in the production and use of energy, in the maintenance of metabolic homeostasis, and in the immune response in the brain.

There are several possible mechanisms of inflammaging. Firstly, the inflammaging processes may be caused by the endogenous host-derived cell debris (damage-associated molecular patterns (DAMPs), i.e., damaged organelles, cells, and macromolecules) that accumulate with age as a consequence of both increased production and impaired elimination [8]. Secondly, aging cells and various inflammatory factors (termed the senescence-associated secretory phenotype or SASP) which they produce may be the chronic inflammation stimulators. Cellular senescence is a response to various stress factors and damages. Aging cells accumulate in various tissues where they contribute to the development of many pathological changes, for example modifying the tissue microenvironment and altering the function of nearby normal or transformed cells. Visceral adipose tissue (VAT) is the main place of senescent cell accumulation and is also a source of proinflammatory cytokines such as IL-6 and TNF- $\alpha$ [13]. Moreover, an excess and changes in the distribution of visceral adipose tissue and the composition and functioning of the lipids have clinical consequences such as metabolic syndrome. Metabolic syndrome is related to insulin resistance 
and impaired glucose tolerance, which lead to type 2 diabetes, obesity, dyslipidemia, elevated blood pressure, and activation of the pro-thrombotic and pro-inflammatory processes that lead to atherosclerosis and chronic inflammation [14, 15]. Studies of the association of distinct abdominal adipose tissue with the cardiometabolic risk factors and metabolic syndrome showed that metabolic syndrome individuals had significantly lower adiponectin levels and significantly higher levels of resistin, leptin, TNF- $\alpha$, IL-6, intercellular adhesion molecule (ICAM), monocyte chemotactic protein-1 (MCP-1), and oxLDL than the control group. The results confirmed that deep subcutaneous adipose tissue (dSAT) is associated with increased inflammation and oxidative stress, suggesting that dSAT is an important determinant of metabolic syndrome [16]. A variety of adipokines, particularly interleukins, are considered to be associated with inflammatory processes that can lead to dementia and cognitive impairment. It is postulated that adipokines as biomarkers may enhance understanding of late-onset dementia risk over the life course, as well as the clinical progression of prodromal and manifest dementias [17]. Increasing evidence and clinical and epidemiological studies suggest an association between metabolic syndrome and type 2 diabetes and $\mathrm{AD}[18,19]$. It is indicated that diabetic patients have increased risk of developing $\mathrm{AD}$ and $\mathrm{AD}$ brains exhibit defective insulin signaling [20]. Thirdly, inflammaging may be caused by hyperactivity of the blood coagulation that increases the risk of thrombosis in the elderly. And finally, the reason for the development of inflammaging is the aging immune system (immunosenescence). Immunosenescence involves age-related remodeling changes in the organization of lymphoid organs and functions of immune cells, which have been associated with reduction of the degree of adaptive immunity and hyperactivity of the innate immune response. Immunosenescence may result from exposure to different pathogens and antigens over a lifetime, intracellular changes in immune cells, and genetic predisposition. Chronic infections, such as cytomegalovirus (CMV), human immunodeficiency virus (HIV), and Epstein-Barr virus (EBV) are known to impair the immune parameters [21-24]. Decline in cell-mediated immunity may in turn cause the age-related increased incidence of Herpes zoster (varicella zoster virus, VZV) and its complications in the elderly which is a worldwide growing problem for patient, cares, healthcare systems, and employers [25].

The term "neuroinflammation" means an inflammatory response originated in the CNS (brain and spinal cord) after injury by non-infectious or infection factors, with an accumulation of glial cells (microglia, astrocytes). The critical aspects in understanding neuroinflammation and its physiological, biochemical, and behavioral consequences are its context, course, and duration [4]. The active parts of the neuroinflammatory process take cytokines, chemokines, and complement and pattern-recognition receptors (PRR) that are produced and expressed by microglia and astrocytes [26, 27]. All the neuroinflammatory and regulatory processes within the CNS are generally initiated to prevent any disturbance of cell homeostasis. An acute inflammatory response in the CNS is caused by rapid and early activation of the glial cells as a response to different irritants (toxic proteins, infectious agents, stroke, depression, hypertension, diabetes, dementia, and other neurodegenerative disorders), which leads to repair of the damaged area of the brain. However, if harmful agents act persistent, an acute inflammatory state of the brain becomes chronic, and activation of glial cells is exaggerated, which leads to tissue degeneration. Moreover, chronic inflammation in the brain dysregulates mechanisms for clearing misfolded or damaged neuronal proteins resulting in tau-associated impairments of axonal integrity and transport, accumulation of amyloid precursor protein (APP), formation of paired helical filaments, and synaptic dysfunction. All these events precede and cause a prominent neurodegeneration and cognitive decline $[27,28]$. Increased levels of inflammatory mediators, such as IL-1, IL-6, or TNF- $\alpha$, are one of the biomarkers of human aging and closely associated with impaired mechanisms of ROS removal as well as leveling effects of their actions. Overgeneration of ROS leads to oxidative stress and induces NFKB expression, a key activator of inflammatory reactions. It is clear, therefore, that chronic inflammation in the CNS will occur frequently in people with age-related diseases [27]. Although the mechanisms that ultimately lead to neurodegeneration are different in each neurodegenerative disease (AD, PD, ALS, etc.), chronic inflammation is typically a prominent feature in the progressive nature of neurodegeneration. Thus, the resolution of inflammation is an active process, which is dependent on well-orchestrated innate and adaptive immune responses, and the neuroinflammatory reactions may therefore be beneficial or detrimental, depending on their duration and strengths of activation (Fig. 1) [29].

\section{Innate and Adaptive Immune Response in the CNS}

The innate and adaptive immune systems actively participate in CNS surveillance, which is critical for the maintenance of CNS homeostasis and can facilitate the resolution of infections, degeneration, and tissue damage [30]. To understand neuroinflammation, it is important to distinguish innate and adaptive immune response in the CNS [5]. Innate immune reactions activated in the CNS lead to many essential modifications in the tissue microenvironment, e.g., changes in gene expression, which are normally repressed under physiological conditions and are only induced when cells are stressed, cellular differentiation, cellular composition and promotion of the recruitment of peripheral innate immune cells (macrophages, neutrophils) through BBB and adaptive immune cells (T cells and B cells). The main resident immune cells within the CNS are microglia, 


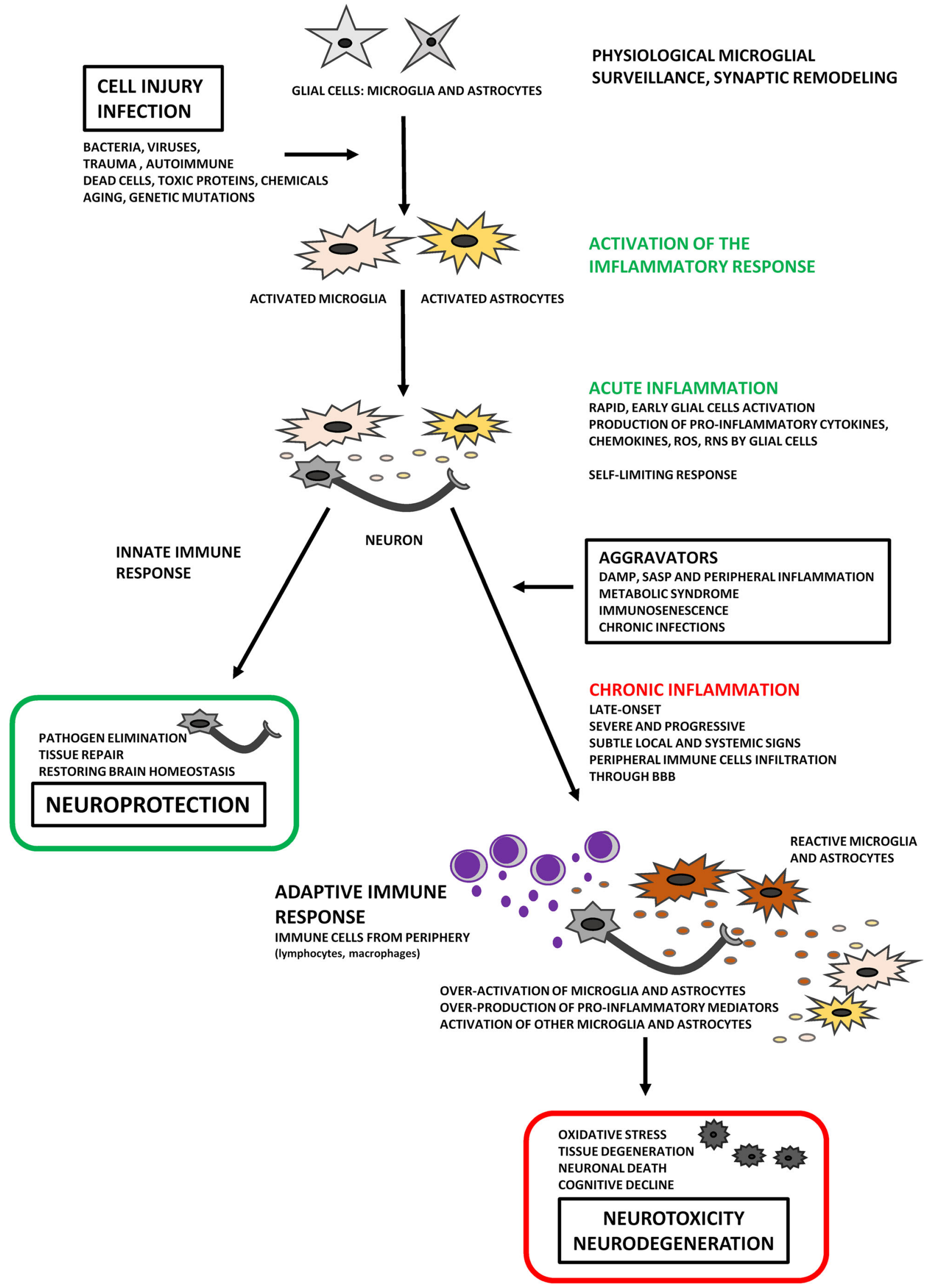


4 Fig. 1 "Two faces" of neuroinflammation. Chronic inflammation is typically a prominent feature in the progressive nature of neurodegeneration. Neuroinflammation is an active process, which is dependent on well-orchestrated innate and adaptive immune responses, and the neuroinflammatory reactions may therefore be beneficial or detrimental, depending on their duration and strengths of activation

complemented also by CNS-derived macrophages from meninges, choroid plexus, and perivascular space, which provide innate immunity [31]. In non-pathological conditions, microglia scan the local microenvironment constantly and detect CNS damage. In this deactivation state, microglia release many immune (anti-inflammatory) and growth (neurotropic) factors that influence astrocytes and neurons. Cell injury or pathogen infection leads to microglial activation, morphological changes, and production of pro-inflammatory mediators. Thus, microglia are the earliest responders to any changes in the CNS [5, 32]. Developing an inflammatory response next stimulates the immune system (innate immune response), to eliminate stress stimulus. The initiation of an immune response may next involve the development of adaptive immunity. In the healthy brain, this early inflammatory response is self-limited, after the stimulus is terminated (phagocytosis of pathogens, abnormal protein deposits, debris or apoptotic cells) and described as beneficial and neuroprotective [33]. A recently characterized transient form of immune activation is euflammation, which can be induced by repeated subthreshold infectious challenges and causes innate immune alterations without overt neuroimmune activation. Thus, euflammation is associated with reduced inflammation and leads to neuroprotection [34, 35].

However, if inflammatory reactions are uncontrolled and chronic, it results in microglial overactivation (reactive microglia), which releases large amounts of inflammatory agents. This attracts other cells, microglia, and astrocytes. Innate inflammation is reported in AD, PD, ALS, and other neuropathologies [33]. Reactive microglia and astrocytes potentially cause injury to the $\mathrm{BBB}$, which become more permeable for periphery immune cells, and neuronal impairment. The release of cytokines, chemokines, reactive oxygen species, and pro-inflammatory mediators by reactive glial cells leads to neurotoxicity and may accelerate neurodegeneration. Moreover, recruited peripheral immune cells (mainly lymphocytes) increase inflammatory response in the CNS by releasing more inflammatory mediators. Indeed, most CNS pathologies are often connected with abnormal microglial activation. An early phase of microglial activation is essential for the effective removal of toxic agents that could be detrimental for the brain. However, chronic microglial activation is connected with the overproduction of pro-inflammatory mediators which might override the beneficial effect of these cells [29].

It is worth noting that until now it was believed that neuroinflammatory response reflects systemic inflammation, which leads to the common view that entry of circulating immune cells to the CNS could only accelerate the parenchymal damage. González and Pacheco summarize the results of several studies showing that CD4(+) T cells infiltrate the CNS in many neurodegenerative disorders, in which their participation has a critical influence on the outcome of microglial activation and consequent neurodegeneration [36]. In fact, the CNS is constantly surveyed by circulating immune cells within the CSF, which entered into the brain through choroid plexus. The immune cell content of healthy CSF is estimated to consist of approximately $90 \%$ T cells, 5\% B cells, 5\% monocytes, and $<1 \%$ dendritic cells [37]. In the physiological state, activated $\mathrm{T}$ cells, along with circulating and local innate immune cells, patrol the CNS and support brain plasticity, both in health and in response to CNS trauma. Schwartz and colleagues $[29,38,39]$ demonstrated that the improvement of the CNS from acute damage is non-tissue autonomous and requires the involvement of circulating leukocytes, which are needed also for fighting off neurodegenerative conditions and which brought to appreciation the pivotal role of CNSspecific T cells in CNS maintenance and repair. Authors proposed a "protective autoimmunity theory" as an essential physiological mechanism for CNS protection, repair, and maintenance in both health and pathological diseases. This theory assumes a well-controlled generation and activation of CNS-specific T cells is a purposeful process, and only when it is dysregulated these cells become destructive. Yet, it is not confirmed whether protective autoimmunity is a more general phenomenon which occurs in tissues other than the CNS.

Importantly, inflammation is not only a pathological reaction that should be completely eliminated. The local inflammatory response and the innate and adaptive immune reactions are closely related with the etiology of each disease. Moreover, the inflammatory response involves a delicate balance between the innate and adaptive immune systems to deal with inflammatory stimuli $[4,29]$.

\section{Microglia and Astrocytes as Key Designers of the Resolution of Inflammation}

\section{Microglia}

Glial cells, described as non-excitable cells of the CNS, are a highly heterogeneous population, which initiate, participate, and regulate many important brain functions. Any discussion of neuroinflammation focused on the role of microglia and participation of astrocytes. Microglia, firstly described as brain-resident phagocytes, derive from the mesenchyme, in which myeloid stem cells give rise to cells, which migrate to the CNS and go through appropriate transformations [40, 41]. Currently, microglia are considered as the resident 
mononuclear phagocytes of the CNS, belonging to the glial system of non-neuronal cells. Microglia are broadly distributed throughout the brain, retina, optic nerve, and the spinal cord; however, they mainly reside in the hippocampus and gray matter and account for 5-20\% of the total glial cell population within the CNS parenchyma. Microglia have an active role in immune surveillance. Over a decade ago, it was shown that under physiological conditions, microglia are not immunologically quiescent cells as previously believed and confirmed that they are the most dynamic CNS cells. Thus, microglia are now characterized as highly motile cells that contact synapses [42]. Microglia are highly specialized cells, which can either trigger neuroinflammatory pathways leading to gradual neurodegeneration or promote neuroprotection, downregulation of inflammation, and stimulation of neuron repair. Depending on the stage and context of any given lesion, one of these mechanisms prevails [43]. Based on many pathophysiologic studies, it is postulated that there are three different phenotypic states of microglia: (a) resting, ramified; (b) activated non-phagocytic (antigen-presenting cell (APC)like) engaged in CNS inflammation; and (c) reactive, phagocytic, and present in areas of trauma or infection [44].

\section{Physiological Surveillance}

Microglia are considered among the most versatile cells in the body, possessing the capacity to morphologically and functionally adapt to their ever-changing surroundings. Even in a steady state (microglia M0), the processes of microglia, "resting microglia" or rather "surveying microglia", are highly dynamic and they perpetually scan the CNS. Recent investigations show fundamental roles for microglia in the control of neuronal proliferation and differentiation, as well as in the formation of synaptic connections [27, 45, 46]. Microglia are key regulators of synaptic remodeling during development and in the adult CNS via non-cell-autonomous mechanisms [47]. In the non-pathological brain, microglia mature and develop a ramified morphology characterized by motile processes that constantly monitor their immediate surrounding by extending and retracting their processes. Microglia are closely linked with neurons and determine their appropriate functioning (maturation and regeneration) by releasing several growth factors important for the proper development of the CNS. Microglia may play an important role in the remodeling of the brain by removing apoptotic neurons [48]. They were shown to be involved in the phagocytosis of synaptic elements during all stages of life. Microglia have a central role in the pruning of synapses by specifically engulfing the degenerating neurites of inappropriate connections. Stimulation of microglial phagocytosis with exosomes pointed out that exosomes may be a regulator of synapse elimination [49]. Exosomes are naturally occurring nanovesicles, which are implicated in the transfer of messenger RNA (mRNA), microRNAs (miRNA), lipids, and proteins between cells which lead to modifications of the functions of recipient cells. Bátiz et al. [50] present the molecules that could be expressed or secreted in exosomes under physiological or pathological conditions by CNS cells. Well-regulated communication between cells is essential to ensure brain homeostasis and plasticity. In healthy neurons, intercellular information transfer through exosomes acts as a unique mechanism for local and possibly systemic interneuronal transfer of information within functional brain networks [51]. Exosomes are actively involved in the communication between neuron and glial cells and between particular glial cells. It was shown that exosomes secreted by oligodendrocytes are endocytosed by neurons what improve neuronal metabolism and viability under conditions of cell stress (oxidative stress or lack of nutrients) [52]. Current studies confirmed that exosomes are present in the human CSF and may exert their function in brain sites located far from its secretion site. It is worth noticing that proteins related to the neuropathology of certain neurodegenerative diseases, like AD or PD, have been found in the exosomes from CSF samples [51]. Exosomes are also investigated to be involved in the processing of the APP which is associated with AD. These vehicles have been shown to contain full-length APP and several distinct proteolytically cleaved products of APP, including A $\beta$ [53]. Moreover, Turola et al. report that microglia-derived exosomes can stimulate neuronal activity and participate to the propagation of inflammatory signals. They suggest that exosomes represent a secretory pathway for the inflammatory cytokine IL- $\beta$, and this process is activated by the ATP receptor P2X7 [54]. Thus, exosomes are considered as novel types of intercellular messengers that play important roles in cell function, disease, and immunomodulation $[50,55]$.

Microglia are also involved in the formation of learningdependent synapses in the mature brain, as well as maturation and plasticity of excitatory synapses [42]. Wang et al. [56] investigated the constitutive role of microglia by depleting microglia from the mouse model of retina. Their results showed that sustained microglial depletion leads to the degeneration of photoreceptor synapses in the outer plexiform layer and causes a progressive functional deterioration in retinal light responses. They suggest that microglia are constitutively required for the maintenance of synaptic structure in the adult retina and for synaptic transmission underlying normal visual function. In the steady state, in the uninjured CNS, resting microglia contribute to neurogenesis processes, remyelination, and neuroprotection and also support tissue repair and are involved in the maintenance of brain homeostasis. The heterogeneity of microglia in serving housekeeping 
duties, sensing environmental signals, and organizing their (mostly) adequate responses to a disturbed CNS homeostasis is discussed by Gertig and Hanish [57].

\section{Inflammatory Activity}

Microglia are very reactive cells; any changes in the CNS immediately lead to the activation, proliferation, and morphological changes of the cell structure [27, 58].In an early phase of acute neuroinflammatory response, the number of microglia increases immediately, and this is part of the microglial activation program [59]. As mentioned, microglia are the first line of defense against pathogens that invade and injure the CNS, contributing to both innate and adaptive immune responses locally. As phagocytes, microglia release cytotoxic factors and may act as APC. Microglia can be activated by a broad range of stimuli, including nerve injury, infection, ischemia, toxic insults, and trauma as well as different chemicals, cytokines, or proteins [60]. Moreover, C1q and $\mathrm{C} 3 \mathrm{~b}$ complement cascade proteins can activate innate immune response in microglia, thus inducing more vigorous response [43]. Among the spectrum of molecular targets, microglia sense and act on glycolipids, lipoproteins, peptides, nucleotides, $\mathrm{A} \beta$, and other abnormally processed proteins, inflammatory cytokines, and neurons, the strongest inducers of microglial activation [61]. Luo and Chen [60] report that many studies emphasize the role of crosstalk between microglia and neurons in microglial activation. Healthy or injured neurons send different signals that determine neuroprotective or neurotoxic microglial activities. Activated microglia produce pro- and anti-inflammatory cytokines like TNF- $\alpha$, IL$1 \beta$, IL-4, IL-6, IL-10, IL-12, IL-13, IL-15, IL-18, IFN- $\alpha$, IFN- $\gamma$, TGF- $\beta$, M-CSF, and GM-CSF; chemokines (IL-8, Gro $\alpha$, IP-10, MIP-1 $\alpha$, MIP-1 $\beta$ ); growth factors such as fibroblast growth factor (FGF), platelet-derived growth factor (PDGF), brain-derived neurotrophic factor (BDNF), and nerve growth factor (NGF); ROS; RNS; inflammatory markers (C-reactive protein, serum amyloid $\mathrm{P})$; proteases $(\alpha$ antitrypsin, $\alpha$-antichemotrypsin); and complement system proteins [58, 61, 62]. Microglial activation is a complex process and may proceed in three different ways (microglia polarization), leading to (i) classical activation (M1), which is stimulated by IFN- $\gamma$, (ii) alternative phagocytic/ neuroprotective activation (M2, now known as M2a with a subcategory M2b), which is stimulated by IL-4 and IL-13, and (iii) acquired deactivation (known as M2c), which is stimulated by TGF- $\beta$, IL-10, and apoptotic cells [63, 64]. M1 and M2 phenotypes, respectively, belong to the type (b) or (c) microglial states. Further, the factors which cause polarization to $\mathrm{M} 1$ or M2 reinforce the maintenance of that phenotype in a cycle-like manner [44]. Different antigenic markers characterize the microglial phenotypes, including HLA-DR, CD68, or ionized calcium-binding adaptor molecule-1 (IBA-1) as well as CD 14, CD 45, or ferritin [64]. The role of microglia is still debatable in terms of neuroprotection and neurodegeneration. Their dual activity is connected with the phenotype changing and interactions with other immune cells (astrocytes, T lymphocytes) [65].

In non-pathological states, microglia can support neurons by releasing neurotrophic factors and are capable of assisting in synaptic plasticity and structure remodeling [66]. Moreover, microglia play an important role in regulating neuronal network excitability. In the review of Ferrini and Koninck [67], the mechanisms by which BDNF, released from microglia, control neuronal excitability are described. They showed that microglia alter neuronal excitability by affecting synaptic inhibition mediated by $\gamma$-amino-butyric acid (GABA) and glycine (Gly) which activate ionic channels $\left(\mathrm{GABA}_{\mathrm{A}} \mathrm{R}\right.$ and GlyR) permeable to anions, like chloride $\left(\mathrm{Cl}^{-}\right)$and bicarbonate $\left(\mathrm{HCO}_{3}{ }^{-}\right)$. Mild activation of microglia connected with the release of neurotrophic factors and cytokines, which translate environmental into molecular signals [68], has been shown to promote synaptic plasticity and promote neurons repair [69]. For example, certain basal levels of TNF- $\alpha$ are required for the development of normal cognition [70]. Steinmetz and Turrigiano [71] confirmed that glialderived TNF- $\alpha$ is critical for maintaining synapses in a plastic state in which synaptic scaling can be expressed. Interestingly, the beneficial microglial state resembles an activated morphology and protein expression, but the function is distinct from a classic pro-inflammatory response. In general, microglial functions and activation are beneficial and necessary for a healthy CNS. If microglia become neurotoxic, it is always connected with the loss of the beneficial functions and/or a shift to a reactive phenotypic state. In this stage, the mechanism through which microglia are thought to cause neuron damage is through the excessive and inappropriate release of toxic factors [72].

The classical, M1, microglial activation pathway that initiates tissue defense mechanism is beneficial for the survival of the organisms and leads to the restoration of normal tissue homeostasis [63]. Many disease proteins and environmental toxicants trigger a toxic microglial response because they are misinterpreted as a pathogen M1 pathway which is connected with the activation of interferon regulatory factors (IRFs), especially IRF5, which in turn activates genes for proinflammatory cytokines IFN- $\gamma$, IL- $1 \beta$, TNF- $\alpha$, IL-6, IL-18, IL-12, and IL-23. This process is also related to the elevated level of NO, ROS, RNS, and chemokine and loss of phagocytic activity and support of defense-oriented Th1-type immune reactions [73]. Inflammatory agents regulate innate immune defense and modify synaptic function. To reduce the defense response and promote repair of the damage brain tissue, replacement of lost and damaged cells and restructuring of the damaged extracellular matrix are essential. The decrease in the activation of PRR and bystander injury caused 
by pro-inflammatory cytokines results from the reducing pathogen levels and the increasing catabolism of proinflammatory mediators. Moreover, during innate immune response in the brain tissue, invasion of monocytic cells from the periphery is also observed. Newly recruited macrophages phagocytose dead or dying immune cells then exit the tissue via the lymphatic system. This removal of the proinflammatory immune cells allows to restore tissue homeostasis [63]. However, strong activation of microglial cells can be associated with cytotoxicity. Overactivation of microglia, when they continually produce inflammatory mediators (chronic activation), can directly damage neurons and accelerate neurodegeneration [61]. Lull and Block suggest that many disease proteins and environmental toxicants trigger a toxic microglial response because they are misinterpreted as a pathogen $[72,74]$. Longstanding microglial activation followed by sustained release of inflammatory mediators, which aid in enhanced nitrosative and oxidative stress, leads to chronic inflammation. The long-drawn release of pro-inflammatory mediators propels the inflammatory cycle by increased microglial activation and proliferation, thus stimulating enhanced release of pro-inflammatory agents [75]. Cytokines produced by microglia can stimulate another glial cells which next increase the pool of neurotoxic cytokines. Large amounts of pro-inflammatory cytokines, NO, ROS, and RNS lead to mitochondrial respiratory chain failure in glial cells and neurons [76]. Additionally, ROS may cause mutations in mitochondrial DNA (mtDNA), which in turn increase ROS production and deregulation of $\mathrm{Ca}(2+)$ homeostasis [43, 77]. Inflammatory factors secreted by microglia under the influence of $A \beta$ may also increase the production of the $A \beta$. Impairment of intercellular communication leads to neurodegeneration and is connected with development of $\mathrm{AD}, \mathrm{PD}$, MS, ALS, Huntington's disease, HIV dementia, and others $[65,72]$. Moreover, extensive oxidative stress is linked with lipid peroxidation and oxidative modification of proteins [78]. Numerous studies confirm that the pro-inflammatory phenotype of microglia contributes to a reduction in the number of neurons, destabilizes synaptic connections, and impairs neurogenesis [79]. In fact, microglia present a tendency for a chronic pro-inflammatory response, rather than demonstrating a resolution of the innate immune response, as is common in the peripheral immune system. It is suggested that this tendency is a key factor driving progressive neuron damage, contributing to the chronic nature of neurodegenerative diseases [72]. As demonstrated, inhibition of microglial overactivation results in suppression of neurotoxic events and increases survival of neurons in early stages of neurodegeneration.

To stop the inflammatory phase of classically activated microglia, the change of macrophage activation state from pro-inflammatory gene profile to anti-inflammatory is essential. Microglia activated through the alternative, M2 pathway are characterized by increased level of anti- inflammatory cytokines, like IL-4, IL-10, IL-13, TGF- $\beta$, IGF, NGF, and BDNF, and increase in phagocytic activity without NO production. This phenotype assists Th2-type immune responses, resolves inflammation, and supports tissue repair and reconstruction $[63,73]$. It is suggested that polarization to M2 microglia promotes remyelination. Recently, a new homeobox protein (msh-like homeobox-3 (Msx3))-dependent mechanism for driving microglia M2 polarization was described [80]. Increased phagocytic features allow for effective removal of $A \beta$ deposits, which indicates the neuroprotective role of M2 microglia [26, 63]. The lack of an appropriate $\mathrm{M} 2$ response might be an important mechanism underlying neurodegeneration [81].

The third microglial activation state, associated with antiinflammatory and repair activities, is an acquired deactivation (M2c phenotype). Both M2 phenotype and acquired deactivation downregulate innate immune response and present similar gene profiles. For that reason, many investigators include these two phenotypes into one category, but this is not justified. The explanation of the differences in acquired deactivation and alternative activation of microglia was previously shown by Colton [63]. In contrast to M2 activation, acquired deactivation is challenged by apoptotic cells, TGF- $\beta$ and/or IL-10. Microglia are the main phagocytes engaged in the removal of apoptotic cells, and this mechanism is linked to suppression of pro-inflammatory cytokine production (immunosuppression of macrophage functions). TGF- $\beta$ and IL-10 are released by several brain cell types including astrocytes and microglia. Additionally, an uptake of apoptotic cells increases the production of TGF- $\beta$ and IL-10 by microglia. TGF- $\beta$ and IL-10 have growth factor properties and promote survival of neurons and other cells through an activation of anti-apoptotic proteins, increasing tight junction at the BBB.

In the human brains, the classically, inflammatory activated microglia (M1) and an alternative, anti-inflammatory phenotype (M2) are present and are hybrids of these two phenotypes. It was shown that at the same time, different microglia can be at different stages of activation, differentiation, and function [64]. Currently, it is postulated that disturbances in the switching of microglial phenotypes may be one of the reasons for the development of chronic inflammation and neurodegenerative diseases. As a result, the relation of proinflammatory to anti-inflammatory phenotype is invalid, and it is known that microglial phenotype M1 is the biggest source of NO, ROS, RNS, and pro-inflammatory cytokines in the CNS that are disruptive to the adjacent neurons [82]. New approach to therapies in neurodegenerative diseases should also be based on to administer agents that inhibit the inflammatory stimulation of microglia or modulation of microglial activities by converting the inflammatory on antiinflammatory phenotype [83]. Moreover, as suggested by Latta et al., evaluation of plasma proteins that are indicative of microglial immune profile (M1/M2) may allow for 
appropriate selection of patients for trials and immune therapy (personalized therapy) [84]. Microglial cell polarization may be regulated by many molecular signals, among which microRNAs have recently been identified. It is suggested that microRNA-155 (miR-155) regulates pro-inflammatory responses in both blood-derived and central nervous system (CNS)-resident myeloid cells [85]. Furthermore, microRNA124 (miR-124) injection resulted in a significantly increased neuronal survival and a significantly increased number of M2like polarized microglia/macrophages [86]. The role of miR124 in the adaptation of microglia and macrophages to the CNS microenvironment and the influence of miR-155 and miR-124 on the polarization of macrophages are intensively discussed by Ponomarev et al. [87].

\section{Astrocytes}

The second, most important glial cells are astrocytes. Astrocytes are ubiquitous and heterogeneous types of glial cells, which occupy 25 to $50 \%$ of the brain volume. Astrocytes are stellate cells, but their morphology differs depending on their development stage, subtype, and localization. Gray matter astrocytes are the protoplasmic ones, which exhibit short branches, whereas in the white matter, astrocytes exhibit long unbranched processes and are usually called fibrous astrocytes $[88,89]$. Astrocytes are the only cells in the brain that contain the energy storage molecule glycogen, the largest energy reserve of the brain. They also contain a unique protein called glial fibrillary acidic protein (GFAP). It was presented that overexpression of GFAP can be lethal and is responsible for several neurodegenerative diseases, like Alexander disease [90, 91]. Astrocytes are multifunctional cells that control the brain homeostasis and are responsible for proper neuron functioning [58]. Their neuro-supportive role and participation in the formation and functioning of $\mathrm{BBB}$ are well documented. Astrocytes have an influence on $\mathrm{pH}$, ion homeostasis and blood flow and regulate oxidative stress. Furthermore, these cells contribute to synaptogenesis, modulate neuronal conductivity, and regulate neural and synaptic plasticity [88, 92, 93]. Under physiological conditions, astrocytes can also metabolize $\mathrm{A} \beta$. The receptor for advanced glycation endproducts (RAGE), expressed by astrocyte, binds $\mathrm{A} \beta$, phagocytoses, and is taken up for lysosomal degradation in order to maintain $\mathrm{A} \beta$ homeostasis [89]. Astrocytes, like microglia, respond quickly on pathology within the CNS. They change the morphology, antigenicity, and function [58]. However, recent investigation suggests the dual role in either clearing and producing $\mathrm{A} \beta$. Zhao et al. demonstrate that cytokines including TNF- $\alpha+$ IFN- $\gamma$ and $A \beta 42$ increase levels of endogenous beta-secretase 1 (BACE1), APP, and A $\beta$ and stimulate amyloidogenic APP processing in astrocytes. These results suggest that mentioned factors promote astrocytic $A \beta$ production, which means that activated astrocytes may represent significant sources of $\mathrm{A} \beta$ during neuroinflammation in $\mathrm{AD}$. On the other hand, exposure to $\mathrm{A} \beta$ causes deleterious consequences on astrocyte functioning [94]. Thus, evidence suggests that astrocytes interact with neurons both chemically and physically, supporting their role as pivotal for higher brain functions (learning and memory). However, astroglial, as well as microglial, dysfunction following brain injury can alter mechanisms of synaptic plasticity and may be related to an increased risk for persistent memory deficits [69].

The interactions between astrocytes and microglia turn microglial inflammatory response. However, this mechanism could be impaired in inflammatory state where downregulation of the astrocyte-suppressive function may lead to microglial overactivation and release large amounts of proinflammatory cytokines [65]. The numerous activities of astrocytes, similarly as microglia, following injury can either promote recovery or underlie the pathobiology of memory deficits [69]. Several studies investigate that the pathological changes of the astrocytes are associated with the occurrence of neurodegenerative diseases. Large amounts of astrocytes were found in the senile plaques in the brains of patients with $\mathrm{AD}$ and murine models, which is very characteristic of the disease progression and is described as reactive astrogliosis [27]. Astrocyte reactivity (astrogliosis) is characterized by three hallmarks, GFAP elevation, hypertrophy, and increased proliferation, and depends on interplay with activated microglia [26, 69]. Generally, astrocytes can be activated by various pathological factors, including $A \beta$, and pro-inflammatory cytokines such as IL-1 $\beta$. Moreover, and the most important, is that astrocytes may be activated also by reactive microglia. Activation and inflammatory response of astrocytes is the response associated with the expression of many receptors for pro-inflammatory factors, including the receptors for cytokines IL- $1 \beta$ or TNF- $\alpha$ and chemokine. Astrocytes also produce ligands for TLRs. In response to this activation, astrocytic NF- $\mathrm{KB}$ is activated, and these cells release large amounts of pro-inflammatory cytokines, NO, and other neuroinflammatory agents, contributing to the increase in neuroinflammation in the brain and neuronal death. Astrogliadependent toxicity was observed by Efremova et al. when immortalized murine astrocytes were stimulated with cytokine mix (TNF, IL-1) and the culture medium was transferred to human neurons [95]. The activation of NF- $\kappa B$ in astrocytes is also responsible in mediating the inflammatory process through the expression of adhesion molecules and chemokines which allow for the invasion by peripheral leukocytes, further fueling the inflammatory response [58].

\section{Modulation of Microglial Activity}

Receptors and Intracellular Signaling Pathogens which penetrate $\mathrm{BBB}$ activate a mixed response of microglia characterized by enhanced phagocytosis and pro-inflammatory 
cytokine production, as well as adaptive activation of $\mathrm{T}$ cells. Thus, phagocytic activity of microglia may rescue neurons from degeneration and injury. Reactive microglia remove from the CNS not only pathogens but also damaged cells from neighboring tissues and maintain CNS homeostasis. CD200, expressed on the neuronal membrane, and its receptor CD200R present in the microglia are actively involved in phagocytosis. Interaction between these proteins determine the high threshold of microglial excitability, which allows for control of the inflammatory response in the CNS. The M2 activation pathway leads to increased CD200R expression under IL-4 stimulation. It was also shown, in the brains of the elderly and in AD patients, that the decrease in CD200 expression is age-related, which in turn increases the proinflammatory microglial activity or switch from M2 to M1 phenotype [60]. Microglial activation is also related to cytoskeletal rearrangements that alter the pattern of receptors on the cell surface. Microglial receptors include toll-like receptors (TLRs), which belong to the PRR that recognize PAMP and DAMP, nucleotide-binding domains, the leucine-rich repeat-containing receptors (NOD-like receptors (NLRs)), whose function is dependent on the multimolecular complexes termed "inflammasomes", RAGE, Fc receptors, complement receptor 3, various scavenger receptors, C-type lectin receptor, mannose receptor MRC1, cytokine and chemokine receptors, receptors related to endocytosis (e.g., BIN1, PICALM, CD2AP) and lipid biology (e.g., CLU, ABCA7), several scavenger receptors, or receptors for several neurotransmitters [31, 62]. Moreover, TLR, SCARA1, CD36, CD14, $\alpha 6 \beta 1$ integrin, and CD47 are important receptors for regulating microglial responses to $A \beta$. According to genomewide association studies (GWAS), different gene variants of some of these receptors are associated with an increased risk of late-onset AD (LOAD) [96, 97].

Among PRR in CNS, membrane-bound TLRs, which sense extracellular or endosomally located signals, and NLRs, located within the cytoplasm and sense intracellular signals, are the key innate immune receptors expressed by microglia, macrophages, and astrocytes. NLRs are a part of the multiprotein complex called inflammasomes. Inflammasomes generally have three main components: a cytosolic PRR (which is a member of the NLR family of protein or pyrin and the HIN domain-containing family of proteins (PYHIN)), the enzyme caspase 1, and an adaptor protein that facilitates an interaction between the two [31]. This cytosolic platform enables the activation of caspase 1 which leads to the cleavage and release of pro-inflammatory cytokines. Inflammasomes are essential protein complexes that direct the innate immune system's responses and apoptotic response in the human brain to pathogenic and non-pathogenic stimuli [98]. De Vasconcelos et al. present recent advances in the role of inflammasomes in regulated cell death signaling [99]. Indeed, initiation of the activation of inflammasomes in astrocytes and microglia leads to release in inflammatory factors, IL-1 $\beta$ and IL-18, which next activate more astrocytes and microglia and cause secretion of more inflammatory molecules. Inflammasomes are chiefly known for their roles in maturation and secretion of IL-1 $\beta$ and IL18. These molecules are responsible for the elevation of amyloidogenesis and neurofibrillary tangles (NFTs) in neurons and the recruitment of another immune cells (monocytes, lymphocytes) from the periphery, which are the source of even more pro-inflammatory factors. This feedback loop creates and propels neuroinflammation that leads to $\mathrm{AD}, \mathrm{PD}$, and other neurodegenerative disorders [100]. Many different types of stimuli may be the inflammasome's activators, e.g., viruses, bacteria, fungi, protozoa, microbial proteins, crystalline urea, RNA, Alum, ATP, potassium efflux, $A \beta$, fatty acids, and degraded mitochondrial DNA [100]. In AD pathogenesis, it is postulated that activation of the NLRP 3 inflammasome in microglia by A $\beta$ may promote disease progression $[98,101]$. Thus, NLRP3 is suspected to be a critical determinant of the development of low-grade sterile inflammatory responses during aging [102].

Positron emission tomography showed that microglial activation correlates with $\mathrm{AD}$ progression [103-105]. A $\beta$ plays a pivotal role in the progression of $\mathrm{AD}$ through its neurotoxic and inflammatory effects. $A \beta$ binds to microglia through receptor-mediated phagocytosis and degradation. Binding of $A \beta$ to microglial membrane receptors appears to be a critical step. Activated microglia exert neuroprotection mediated through $A \beta$ phagocytosis in the early stage, whereas, as the disease progresses, they fail in $A \beta$ clearance and exert detrimental effects, including neuroinflammation and neurodegeneration [106-108]. Receptors expressed on microglia alone or with their co-receptors play complementary and nonredundant roles in the interaction with $A \beta$ in $A D$. Pathogenic $A \beta$ aggregate-activated microglia release various neurotoxic inflammatory mediators in classical M1 inflammatory activation [108]. Microglia express pattern recognition receptors, such as CD14 and especially TLRs, which were originally discovered based on their response to invading microorganisms [106]. TLRs are a family of pattern recognition receptors that are expressed by a variety of immune and nonimmune cells [107, 108]. There are at least 13 distinct TLR family members known in mammals, of which the pathogen specificities of 10 (TLR 1-9 and 11) have been identified [108]. Recent studies have pointed out that immune stimulation targeting TLR9 could dramatically attenuate $A \beta$ neurotoxicity and reduce $A \beta$ levels in in vitro and in vivo $A D$ models. Meanwhile, this reduction in amyloid is associated with cognitive improvement in AD mice [109-111]. Very important is that each TLR has a different ligand specificity that is extended through dimerization of the TLRs or additional coreceptors, such as CD14 for TLR4 and TLR2 [109, 112]. Recently, studies have provided evidence that CD14 and TLR2/TLR4 form a receptor complex, and together they 
participate in the inflammatory response induced by $A \beta$. It has been reported that $\mathrm{CD} 14$ binds fibrillary $\mathrm{A} \beta$ but not non-fibrillary $A \beta$. Neutralization with antibodies against CD14 and genetic deficiency of this receptor significantly reduced $A \beta$-induced microglial activation [112]. These results indicate that CD14 along with TLR4 can induce transcription factors such NF-kB nuclear translocation and consequently induce production of pro-inflammatory mediators in murine microglia and human peripheral blood monocytes [113]. Some studies cite crosstalk with NF-kB involving p53 as an example [113]. NF-kB and p53 can both be activated by many of the same stimuli with a common link frequently being DNA-damaging agents, which include ROS [114]. Besides $\mathrm{CD} 14$, there is also a direct interaction between TLR2 and the aggregated $A \beta 42$. TLR2 deficiency reduces $A \beta 42$ triggered inflammatory activation but enhances $A \beta$ phagocytosis in cultured microglia and macrophages [113].

Recent studies focused on beclin 1 protein, which regulates autophagy, phagocytosis, and functioning of the receptors involved in this process in health and disease. Beclin 1 is involved in the degradation of proteins and immune defense. In mouse models of $\mathrm{AD}$ and $\mathrm{PD}$, it has been shown that beclin 1 plays a key role in reducing amyloidosis and neurodegenerative processes. Beclin 1 deficiency results in reduced expression of the CD36 and TREM2 receptors that determine the proper process of phagocytosis. In $\mathrm{AD}$ brains, the expression of beclin 1 is decreased which is associated with ineffective phagocytosis and autophagy. $A \beta$ deposits and the tau protein are not removed, which play a key role in $\mathrm{AD}$ pathogenesis [115-117]. One of the most important recent findings supports a role of immune dysfunction in $\mathrm{AD}$, which is the connection between LOAD risk and TREM2 gene mutations [96]. TREM2, which belongs to the immunoglobulin (Ig) superfamily of receptors, and DAP-12, a type I transmembrane protein, form a receptor signaling complex on the cell surface of microglia, which triggers phagocytosis and the release of reactive oxygen species. TREM2, same as TLR4, can detect both a PAMP and a DAMP. TREM2 is able to bind grampositive and gram-negative bacteria as well as anionic and zwitterionic lipids and interacts with other endogenous ligands on neurons, leading to the direct removal of damaged cells [118-120]. Anti-inflammatory properties of TREM 2 are well known. TREM2 reduces macrophage activation and inhibits cytokine production in response to TLR2 and TLR4 ligands [102]. Moreover, TREM2 is associated with increased phagocytosis and a promotion of a M2-like activation state of microglia, which is thought to have protective effects [121]. Mutations in TREM2, e.g., rare functional variant $(\mathrm{R} 47 \mathrm{H})$ $[122,123]$, cause impaired signaling by the TREM2-DAP12 pathway. The loss of the functionality of the complex leads to altered immune responses in phagocytosis, cytokine production, microglial proliferation, and survival, which in turn direct to the demyelination of neurons and development of dementia, increasing the risk for $\mathrm{AD}$ and other neurodegenerative disorders $[118,119]$. Animal and human studies have indicated that TREM2 variants have been linked to an enhanced ability of microglia to clear $A \beta$ and amyloid plaques. The loss of TREM 2 functions is connected with $A \beta$-associated microgliosis and tau dysfunction [124-126]. Moreover, additional variants of TREM2, described by Colonna and Wang could be related to AD pathology. Based on these investigations, it is postulated that TREM2 variants may be the new key to deciphering Alzheimer's disease pathogenesis [127].

Aging Microglial activation has both detrimental and beneficial effects. Many studies with mouse model of AD suggests that early microglial activation is neuroprotective due to its $\mathrm{A} \beta$ clearance function, but as the disease progresses, proinflammatory cytokines downregulate genes involved in $A \beta$ clearance, promoting $A \beta$ accumulation [97]. Luo and Chen [60] showed the dual nature of microglia. Weather microglia have positive or negative effects on neuronal survival is context-dependent, but the aging has a great impact on microglial function and successive neurotoxicity. Thus, it was shown that the structure of aging microglia changes from a highly ramified morphology to spheroid formation with HLA-DR antigens, shortened and twisted cytoplasmic processes, and instances of partial or complete cytoplasmic fragmentation. This morphological alteration is described as "dystrophy" [59]. Moreover, the number of microglia increases and their layout becomes more irregular. Aging microglia function abnormally. They become less dynamic and more slowly respond to tissue injury [47]. The concept of "microglial aging" was proposed most recently. Microglial senescence is manifested by an altered inflammatory profile and switch from neuroprotective with production of anti-inflammatory mediators in young adult to neurotoxic with production of proinflammatory mediators in the aged brain upon activation [4, 60]. Importantly, chronic inflammation induces microglial aging from middle age. Senescent types of microglia respond incorrectly to stimuli and are driven by the emergence of increased intracellular ROS which activates the redox-sensitive transcription factors (including NFKB) and leads to mitochondrial DNA damage [78]. What is more, the NF- B signaling pathway may be activated by hypoxia and in turn induce microglial aging.

Timing The timing of microglial activation is another determinant of their function, which decides microglia's destructive or neuroprotective role in the CNS [60]. Hamelin et al. [128] investigated, in a prospective study using 18F-DPA-714 PET imaging, the microglial activation in early AD. They showed that microglial activation appears at the prodromal and possibly at the preclinical stage of $\mathrm{AD}$ and plays a protective role in the clinical progression of the disease at early stages. Importantly, the different dynamic profiles of 
microglial activation and their timing in the progression of the neurodegenerative process can be critical in identifying the correct therapeutic window to target microglial activation for disease modification [129].

The Role of Cytokines in Neuroinflammation Cytokines play a key role in the induction and maintenance of neuroinflammation. They activate both microglia and astrocytes, but the duration of cytokine exposure is short and the effect is transient [4]. Activated astrocytes and microglia are in turn the main sources of cytokines in the CNS (Table 1). Numerous studies confirmed that the levels of classical proinflammatory cytokines such as IL-1, IL-6, IFN- $\gamma$, and TNF- $\alpha$ are elevated in chronic neurodegenerative diseases, especially in $\mathrm{AD}$, which significantly contribute to the disease progression $[138,151,153]$. The correlation between $\mathrm{AD}$ prevalence and polymorphisms in IL-1, IL- 6 , TNF- $\alpha$, and MIP- $\alpha$ genes was also demonstrated [154]. Additionally, the level of anti-inflammatory cytokines such as IL-4, IL-10, and IL-13 is generally reduced. Inflammatory state presents in the brains of $\mathrm{AD}$ patients and in transgenic mouse with cerebral amyloidosis, reaching a destructive size, which in turn increases the risk of transition from mild AD to dementia [26]. Thus, it is important that microglial and astrocyte actions are dependent on the nature of the activating stimulus. Smith et al. [138] summarize that microglial phagocytosis of invading pathogens is associated with their release of proinflammatory factors while clearance of apoptotic debris is associated with production of anti-inflammatory factors.

Generally, pro-inflammatory cytokines may directly contribute to neuronal degeneration, induce apoptosis in neurons and glial cells, increase BBB permeability, and promote trafficking of peripheral immune cells into the CNS, which contribute to damage of neurons. Additionally, these cytokines promote the increase in production of factors (ROS, NO) which are toxic for neurons $[138,155]$. TNF is a strong pro-inflammatory stimulator for most cells of the immune system and the most important neuroinflammatory cytokine. In the case of CNS, TNF, released by activated microglia, may recruit periphery immune cells via the BBB into neuronal tissue, which is a critical step for the development of inflammatory diseases. Persistently elevated levels of TNF have been implicated in chronic inflammation and have been associated with neurodegenerative diseases. However, Fischer and colleagues confirmed earlier reports that TNF plays a region-specific and dual role in neurodegenerative diseases $[76,138,151,152]$. They showed that the TNF receptor (TNFR) 1 is predominantly associated with neurodegeneration. Simultaneously, activation of TNFR2 signaling by TNC-scTNF(R2) promotes anti-apoptotic responses and leads to tissue regeneration and neuroprotection $[76,156]$. Neuroprotective or neurodegenerative properties of TNF are also dependent on the concentration. The experiments with the use of primary cultures of astrocytes showed that the combination of proinflammatory cytokines such as TNF- $\alpha$ and IFN- $\gamma$ increases the level of $A \beta 42$ oligomers, APP and $\beta$ secretase. This in turn leads to an increase in the production of $A \beta$. These results indicate that activated astrocytes have a significant impact on the total volume of $A \beta$ in $\mathrm{AD}$ during inflammation [94]. In the brain, IL-1, as an important regulator of the inflammatory cascade, is released primarily by activated microglial cells. It has been observed that IL-1 is the most important cytokine in the early stage of $\mathrm{AD}$ and its level is elevated in CSF and serum of $A D$ patients $[130,134]$. In vitro studies have demonstrated that IL- 1 increases the level APP and A $\beta$, which leads to neuronal cell death [131]. Furthermore, L1 may induce apoptosis, and this appears to be dependent on the presence or absence of additional cytokines (TNF- $\alpha$ and IFN- $\gamma$ ) and signaling molecules [138]. Proinflammatory cytokines, such as IL-1, can mediate in neuronal damage and death by stimulation of IL-6 production, induction in astrocyte iNOS activity, and release in nitric oxide (NO) and its derivative ONOO- [132]. The use of cytokine cocktail IL- $1 \beta+$ IFN- $\gamma+$ TNF- $\alpha$ leads to the production of nitric oxide synthase (NOS-2) and a dangerously large amount of NO through activation of mitogen-activated kinases (MAPKs) by normal human astrocytes [157]. IL-33, a member of IL-1 family cytokines, is a pro-inflammatory cytokine, highly expressed in the CNS by endothelial cells and astrocytes but not by microglia or neurons. Microglia and astrocytes stimulated with IL-33 responded by proliferating and releasing inflammatory molecules such as TNF- $\alpha$, IL- $1 \beta$, and NO as well as the anti-inflammatory cytokine IL-10 [142]. Kempuraj et al. report that IL-33 mediates neurotoxic effects causing neuronal damage and neurodegeneration changes by releasing mentioned pro-inflammatory mediators (NO, TNF) and induction of CCL2 release from mouse astrocytes in vitro [158]. However, IL-33 and its receptor ST2 show both protective (physiologic) and antiinflammatory activities depending upon the concentration and cell types/organ. IL-33 induces microglia and enhance phagocytosis, suggesting a protective role of IL-33 in neurodegenerative diseases [149]. IFN- $\gamma$, as TNF, has a pleiotropic nature. It possesses antiviral activity but also increases TNF activity and induces NO [132]. Interestingly, it was noted that acute but not chronic activation of certain types of immune responses, with shortterm expression of IL-1, IL-6, and TNF, in the brain may be beneficial [58]. IL- 8 exhibits the largest increase in expression of any inflammatory factor in human microglia incubated with amyloid-beta (A $\beta 1-42)$, and this increase is dose-dependent. Elevated levels of IL-8 in the CSF of 
Table 1 Pro- and anti-inflammatory cytokines involved in the inflammatory response in the CNS

\begin{tabular}{|c|c|c|}
\hline Cytokine & Role in the neuroinflammatory response & Literature \\
\hline IL-1 & $\begin{array}{l}\text { Contributes to neuronal degeneration } \\
\text { May induce apoptosis in neurons and glial cells } \\
\text { Increases the level of APP and A } \beta \\
\text { Increases the iNOS activity and NO production by astrocytes }\end{array}$ & [130-133] \\
\hline IL-3 & $\begin{array}{l}\text { Neuroprotective effects against toxic activity of } A \beta \\
\text { Released by peripheral leukocytes and microglia } \\
\text { Microglial activator } \\
\text { Anti-apoptotic activity mediated by Bcl-2 activation in neurons }\end{array}$ & [134-137] \\
\hline IL-4 & $\begin{array}{l}\text { Induces microglia neuroprotective activity and neurogenesis } \\
\text { Suppresses genes for pro-inflammatory cytokines IL-1 and TNF } \\
\text { Switches microglia toward M2a response }\end{array}$ & {$[132,138-140]$} \\
\hline IL-6 & $\begin{array}{l}\text { Multifunctional cytokine } \\
\text { Promotes astrogliosis and activation of microglia } \\
\text { Contributes to neuronal degeneration } \\
\text { May induce apoptosis in neurons and glial cells }\end{array}$ & {$[132,133]$} \\
\hline IL-8 & $\begin{array}{l}\text { Potentiates } A \beta 1-42 \text {-induced expression and production of pro-inflammatory cytokines in microglia } \\
\text { May play a protective role in the AD pathogenesis }\end{array}$ & {$[134,141]$} \\
\hline IL-10 & $\begin{array}{l}\text { The main anti-inflammatory cytokine } \\
\text { Plays an important role in neuronal homeostasis and cell survival } \\
\text { Prevents overactivation and deficiency of the immune system } \\
\text { Inhibitor of IL-1 } \beta \text {, IL- } 6 \text {, and TNF- } \alpha \text { secretion by microglia } \\
\text { Controls the ROS and RNS production }\end{array}$ & {$[132,142]$} \\
\hline IL-12 & $\begin{array}{l}\text { Higher level in sera of EOAD (early-onset AD) patients } \\
\text { Released by glial cells } \\
\text { Regulator of immune responses }\end{array}$ & {$[143,144]$} \\
\hline IL-13 & $\begin{array}{l}\text { Suppresses genes for pro-inflammatory cytokines IL-1 and TNF } \\
\text { Switches microglia toward M2a response }\end{array}$ & {$[132,139]$} \\
\hline IL-15 & $\begin{array}{l}\text { Marker of inflammation in the brain } \\
\text { Microglial activator } \\
\text { Unclear role in AD pathogenesis }\end{array}$ & {$[145,146]$} \\
\hline IL-18 & $\begin{array}{l}\text { Stimulates inflammatory factor production in the brain } \\
\text { Increases tau phosphorylation and neurofibrillary tangle formation } \\
\text { Accelerates aging processes and deteriorate brain cognitive functions }\end{array}$ & {$[147,148]$} \\
\hline IL-33 & $\begin{array}{l}\text { Nuclear alarmin (released after cell injury) } \\
\text { Participates in gene silencing } \\
\text { Amplifier of the innate immune response } \\
\text { Induces glial cells to release inflammatory mediators causing either neuroprotective or neurotoxic } \\
\text { effects (depending upon the concentrations) } \\
\text { Stimulates microglial phagocytosis }\end{array}$ & {$[138,149,150]$} \\
\hline TNF- $\alpha$ & $\begin{array}{l}\text { Master regulator of the immune system } \\
\text { Propagates inflammation } \\
\text { Mediates the passage of periphery immune cells into the brain } \\
\text { Dual activity_-promotes neurodegeneration and apoptosis in neurons and glial cells, and also } \\
\text { tissue regeneration } \\
\text { Increases A } \beta \text { aggregation (as well as IFN- } \gamma \text { ) }\end{array}$ & {$[76,133,151,152]$} \\
\hline IFN- $\gamma$ & $\begin{array}{l}\text { Important pro-inflammatory cytokine in the innate immune system } \\
\text { Strong microglial and astrocyte activator } \\
\text { Overexpression leads to decrease in } \mathrm{A} \beta \text { deposits and infiltration of peripheral monocytes } \\
\text { Both neuroprotective and neurodegenerative action depending on the concentration } \\
\quad \text { (low level induces microglial neuroprotective activity and neurogenesis) } \\
\text { Antiviral activity }\end{array}$ & {$[94,132,151]$} \\
\hline
\end{tabular}

AD patients have also been documented [134, 141]. Moreover, IL- 8 has been reported to potentiate A $\beta 1-42-$ induced expression and production of a number of proinflammatory cytokines in cultured human microglia. Thus, IL- 8 and its receptor CXCR2 contribute to chemotactic responses in AD. The results of Ryu et al. [159] evidence that upregulation of CXCR2 may be linked with microglial-mediated responses which in turn are correlated with neuronal damage in inflamed brain. However, recent studies demonstrate that IL-8 protects neurons possibly by paracrine or autocrine loop and regulates neuronal functions. Although IL-8 alone did not alter neuronal survival, it did inhibit $A \beta$-induced neuronal apoptosis and increase production of BDNF. Therefore, IL-8 may play a 
protective role in the AD pathogenesis [141]. Proinflammatory cytokine IL-12 is produced by microglia in response to cytokines, LPS, or a neurotropic virus [143]. Vom Berg et al. [144], using the APPPS1 AD mouse model, found increased production of the common interleukin-12 (IL-12) and IL-23 subunit p40 by microglia. Genetic ablation of the IL-12/IL-23 signaling molecule $\mathrm{p} 40, \mathrm{p} 35$, or p19 resulted in decreased cerebral amyloid load. Thus, they suggest that inhibition of the IL-12/ IL-23 pathway may attenuate AD pathology and cognitive deficits.

Anti-inflammatory cytokines can suppress proinflammatory cytokine production and action, an effect that is critical to the concept of balance among pro- and antiinflammatory cytokines. Il-10 as well as IL-4 has an antiinflammatory activity and suppress the inflammation through inhibiting the secretion of IL-1 $\beta$, IL- 6 , IL- 8 , IL-12, and TNF- $\alpha$ by microglia [132]. Moreover, IL-10 triggers microglia to M2c deactivation state. Zheng et al. [151] summarized current reports of IL-10 activity in the CNS. On the other hand, recent investigations showed that forced IL-10 expression in brains of APP transgenic mice leads to increased A $\beta$ accumulation and worsening of behavioral deficits. GuillotSestier et al. [142] report that stimulation of microglia by recombinant IL-10 reduces $A \beta$ phagocytosis, whereas IL-10 deficiency increases $A \beta$ uptake by cultured microglia. It suggests that induction of a pro-inflammatory activation state endorses cerebral amyloid clearance. IL-4, as well as IL-13, is considered to be the strongest polarizing cytokine toward an M2a response [139, 140]. The neuroprotective effect of IL-4 might be related also to the inhibition of IFN- $\gamma$ and the consequent decrease in the concentration of TNF- $\alpha$ and NO [132]. IL-3 could play a neuroprotective role in AD. According to recent literature, IL-3 level is reduced in the plasma of AD patients [134]. Zambrano et al. [135, 136] showed that IL-3 provides cellular protection against $A \beta$ neurotoxicity in primary cortical neuronal cells. Moreover, they investigate that IL-3 induces an increase of the anti-apoptotic protein $\mathrm{Bcl}-2$.

MicroRNAs and p53 as the Key Players in Neurodegeneration The cause of AD has not been fully established; a close correlation between sporadic AD and the role played by p53 and microRNA is well documented in many publications [160-165]. The tumor suppressor and nuclear transcription factor p53 regulates major cellular functions, among them DNA synthesis and DNA repair, gene transcription, cell cycle, cellular senescence program, and cell death by apoptosis [160]. In postmitotic neurons, p53 could be activated by various cell stressors, as hypoxia, oxidative stress, viral infections, metabolic stress, and trophic withdrawal, various insults which lead to DNA damage, oncogene activation, and excitotoxicity $[160,161]$. According to severity of the stress signal, p53 protein helps in the cell adaptive response or, finally, triggers cell death program [162]. It is now clear that $\mathrm{p} 53$ plays an important role in neurodegeneration, and many studies reported neuronal cell death being associated with increased level of $\mathrm{p} 53$ in brain tissue cells $[162,166,167]$. Recently, the important function of $\mathrm{p} 53$ in the regulation of cellular metabolic homeostasis is revealed. By activation of its target transcription genes, p53 contributes to the regulation of glycolysis, glutaminolysis, oxidative phosphorylation, fatty acid oxidation, antioxidant activity, autophagy, and mitochondrial integrity [166, 168-170]. Lack of p53 or its abnormal folding affects neuronal function, leading to neuronal dysfunction [163, 171, 172]. P53 transactivates neuronal growth-associated protein-43 (GAP-43), a protein engaged in axonal growth and formation of new connections, and downregulation of GAP-43 expression is perceived as important molecular lesion that progresses with synaptic disconnections and neurodegeneration [173]. It is worth noticing that in cultures of fibroblast from AD subjects, exposure to low (nanomolar) concentrations of amyloid beta 1-40 peptide induced expression of aberrantly folded p53, and unfolded p53 could participate in the early pathogenesis of $\mathrm{AD}$ and would be a specific marker of the early stage of the disease $[163,173]$. Together, data cited above accentuate the role of basal p53 level in the physiological regulation of metabolic, antioxidant, and regenerative processes. On the other hand, increased p53 expression induced by various chronic cellular stressors of moderate forth leads to significant changes in cellular metabolism, signaling, and expression of pro-oxidant target protein p53-inducible genes PIG3, PIG8, and ferredoxin reductase-FDRX [171], and these changes markedly contribute to progression of neurodegeneration.

\section{MicroRNAs and a Crosstalk Between p53 and MicroRNA}

Network MicroRNAs (miRNA) are single-stranded, small (19-23 nucleotides), endogenous, non-coding RNAs that regulate gene expression in eukaryotic cells by inducing translational arrest and degradation of messenger RNAs $[164,174]$. MicroRNAs are proposed to allow organisms and cells to effectively deal with stress $[175,176]$; in response to stress, cells adapt by altering their gene expression programs, upregulating a subset of mRNAs, which modulate the existing pool of mRNAs without any de novo synthesis, that is, by selectively translating certain mRNAs while halting translation of the rest [177]. Since miRNAs can also modulate the translation and/or stability of multiple targeted transcripts, it is assumed that miRNAs play an important regulatory role in coping with a spectrum of stresses, among them an oxidative stress, nutrient deprivation, DNA damage, or oncogenic stress 
$[175,177,178]$. The biological functions of miRNAs depend on the cellular context, i.e., on the differential expression of their target mRNAs in various cells which is preceded by specific action of transcription factors on gene expression. The p53 protein is a transcription factor which functions mainly by regulating expression of target genes; additionally, non-transcriptional functions of p53 are well documented [167-170, 179]. It regulates the expression not only of protein-coding genes but also of noncoding microRNAs, which act as mediators of p53 impact on gene expression. Interestingly, also the expression and activity of p53 itself are under the control of microRNAs [165]. In response to stress, p53 regulates microRNA synthesis and maturation, and the microRNAs participate in diverse cellular regulatory loops that modulate appropriate cellular adaptation $[165,180]$. The transcriptionindependent modulation of microRNA biogenesis maturation and stability, which is carried out through p53 interaction with the processing complex (the Drosha complex), enables fine-tuning of cellular response to DNA damage and to other stresses of various origin [180,181]. Likewise, transcriptionally inactive p53 mutants could interact with the Drosha complex leading to attenuation of several microRNA processing [181].

As p53 is a key player in the response to different types of cellular stress, its influence on several aspects of cell adaptations comprises also a metabolic shift in cells exposed to stress. The important executor of the p53 action on stressed cell is the microRNA network, and crosstalks between $\mathrm{p} 53$ and microRNA induction and processing are important in maintaining cellular homeostasis. Aberrant expression of the p53/microRNA axis leads to diseases, among them also to neurodegenerative processes. Future research on regulation of the p53/microRNA axis promises significant improvement of the repertoire of early diagnostic biomarkers and could open a new avenue for treatment of neurodegenerative disorders such AD.

Neuroinflammation: Friends or Foe? The intrinsic inflammatory response of the CNS is a key player in the protection against CNS insults. The coordinate chain of events that initiate, modulate, and then lead to the resolution of inflammatory response help the CNS to fight against a myriad of local and systemic insults and maintain the brain health. However, in many instances, the delicate balance and control of the neuroinflammatory responses is lost and disease may arise. The imbalance of inflammatory responses in the CNS may be an initiating factor for many neurodegenerative diseases, i.e., Alzheimer's disease. In other instances, the perpetuation of a chronic inflammatory response by activated microglia in response to the buildup of amyloid- $\beta$ in the brain can lead to progressive neurodegenerative changes and neuronal death that ultimately lead to the clinical progression of dementia syndrome in AD. The relevance of neuroinflammation for maintenance of CNS health, as well as its being a player in several disease-initiating events and progression, makes it an interesting target for the development of novel treatment strategies for different CNS disorders.

\section{Compliance with Ethical Standards}

Conflict of Interest The authors declare that they have no conflict of interest.

Open Access This article is distributed under the terms of the Creative Commons Attribution 4.0 International License (http:// creativecommons.org/licenses/by/4.0/), which permits unrestricted use, distribution, and reproduction in any medium, provided you give appropriate credit to the original author(s) and the source, provide a link to the Creative Commons license, and indicate if changes were made.

\section{References}

1. Diack AB, Alibhai JD, Barron R, Bradford B, Piccardo P, Manson JC (2016) Insights into mechanisms of chronic neurodegeneration. Int J Mol Sci 17(1)

2. Chen W-W, Zhang X, Huang W-J (2016) Role of neuroinflammation in neurodegenerative diseases (review). Mol Med Rep 13: 3391-3396

3. Kohan R, Cismondi IA, Oller-Ramirez AM, Guelbert N, Anzolini TV, Alonso G et al (2011) Therapeutic approaches to the challenge of neuronal ceroid lipofuscinoses. Curr Pharm Biotechnol 12: 867-883

4. DiSabato D, Quan N, Godbout JP (2016) Neuroinflammation: the devil is in the details. J Neurochem. doi:10.1111/jnc.13607

5. Waisman A, Liblau RS, Becher B (2015) Innate and adaptive immune responses in the CNS. Lancet Neurol 14:945-955

6. Headland SE, Norling LV (2015) The resolution of inflammation: principles and challenges. Semin Immunol 27:149-160

7. Całkosiński I, Dobrzyński M, Całkosińska M, Seweryn E, Bronowicka-Szydełko A et al (2009) Characterization of an inflammatory response. Post Hig Med Dosw (online) 63:395-408

8. Franceschi C, Campisi J (2014) Chronic inflammation (inflammaging) and its potential contribution to age-associated diseases. J Gerontol A Biol Sci Med Sci 69(Suppl 1):S4-S9

9. Maskrey BH, Megson IL, Whitfield PD, Rossi AG (2011) Mechanisms of resolution of inflammation: a focus on cardiovascular disease. Arterioscler Thromb Vasc Biol 31:1001-1006

10. Shaw AC, Goldstein DR, Montgomery RR (2013) Age-dependent dysregulation of innate immunity. Nat Rev Immunol 13:875-887

11. Franceschi C, Capri M, Monti D, Giunta S, Olivieri F, Sevini F et al (2007) Inflammaging and anti-inflammaging: a systemic perspective on aging and longevity emerged from studies in humans. Mech Ageing Dev 128:92-105

12. Salvioli S, Capri M, Valensin S, Tieri P, Monti D, Ottaviani E et al (2006) Inflamm-aging, cytokines and aging: state of the art, new hypotheses on the role of mitochondria and new perspectives from systems biology. Curr Pharm Des 12:3161-3171

13. Batra A, Siegmund B (2012) The role of visceral fat. Dig Dis 30: $70-74$ 
14. Palmer AK, Tchkonia T, LeBrasseur NK, Chini EN, Xu M, Kirkland JL (2015) Cellular senescence in type 2 diabetes: a therapeutic opportunity. Diabetes 64:2289-2298

15. Skowrońska B, Fichna M, Fichna P (2005) The role of adipose tissue in the endocrine system. Endokrynol Otyłość Zaburz Przem Materii 1:21-29

16. Kim S-H, Chung J, Song S-W, Jung WS, Lee Y-A, Kim H-N (2016) Relationship between deep subcutaneous abdominal adipose tissue and metabolic syndrome: a case control study. Diabetol Metab Syndr 8:10

17. Kiliaan AJ, Arnoldussen IAC, Gustafson DR (2014) Adipokines: a link between obesity and dementia? Lancet Neurol 13:913-923

18. Li X, Song D, Leng SX (2015) Link between type 2 diabetes and Alzheimer's disease: from epidemiology to mechanism and treatment. Clin Interv Aging 10:549-560

19. van Dijk G, van Heijningen S, Reijne AC, Nyakas C, van der Zee EA, Eisel ULM (2015) Integrative neurobiology of metabolic diseases, neuroinflammation, and neurodegeneration. Front Neurosci 9:173

20. Kim B, Feldman EL (2015) Insulin resistance as a key link for the increased risk of cognitive impairment in the metabolic syndrome. Exp Mol Med 47:e149

21. Weltevrede M, Eilers R, de Melker HE, van Baarle D (2016) Cytomegalovirus persistence and T-cell immunosenescence in people aged fifty and older: a systematic review. Exp Gerontol 77:87-95

22. Bauer ME, Fuente MD la (2016) The role of oxidative and inflammatory stress and persistent viral infections in immunosenescence. Mech Ageing Dev 7

23. Nasi M, Pinti M, De Biasi S, Gibellini L, Ferraro D, Mussini C et al (2014) Aging with HIV infection: a journey to the center of inflammAIDS, immunosenescence and neuroHIV. Immunol Lett 162(1 Pt B):329-333

24. Sansoni P, Vescovini R, Fagnoni F, Biasini C, Zanni F, Zanlari L et al (2008) The immune system in extreme longevity. Exp Gerontol 43:61-65

25. Johnson RW, Alvarez-Pasquin M-J, Bijl M, Franco E, Gaillat J, Clara JG et al (2015) Herpes zoster epidemiology, management, and disease and economic burden in Europe: a multidisciplinary perspective. Ther Adv Vaccines 3:109-120

26. Heneka MT, Carson MJ, Khoury JE, Landreth GE, Brosseron F, Feinstein DL et al (2015) Neuroinflammation in Alzheimer's disease. Lancet Neurol 14:388-405

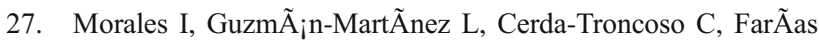
GA, Maccioni RB (2014) Neuroinflammation in the pathogenesis of Alzheimer's disease. A rational framework for the search of novel therapeutic approaches. Front Cell Neurosci 8:112

28. Lim SL, Rodriguez-Ortiz CJ, Kitazawa M (2015) Infection, systemic inflammation, and Alzheimer's disease. Microbes Infect 17: 549-556

29. Schwartz M, Baruch K (2014) The resolution of neuroinflammation in neurodegeneration: leukocyte recruitment via the choroid plexus. EMBO J 33:7-22

30. Russo MV, McGavern DB (2015) Immune surveillance of the CNS following infection and injury. Trends Immunol 36:637-650

31. Walsh JG, Muruve DA, Power C (2014) Inflammasomes in the CNS. Nat Rev Neurosci 15:84-97

32. Barichello T, Generoso JS, Goularte JA, Collodel A, Pitcher MR, Simões LR et al (2015) Does infection-induced immune activation contribute to dementia? Aging Dis 6:342-348

33. Khandelwal PJ, Herman AM, Moussa CE-H (2011) Inflammation in the early stages of neurodegenerative pathology. J Neuroimmunol 238:1-11

34. Tarr AJ, Liu X, Reed NS, Quan N (2014) Kinetic characteristics of euflammation: the induction of controlled inflammation without overt sickness behavior. Brain Behav Immun 42:96-108
35. Liu X, Nemeth DP, Tarr AJ, Belevych N, Syed ZW, Wang Y et al (2016) Euflammation attenuates peripheral inflammation-induced neuroinflammation and mitigates immune-to-brain signaling. Brain Behav Immun 54:140-148

36. González H, Pacheco R (2014) T-cell-mediated regulation of neuroinflammation involved in neurodegenerative diseases. J Neuroinflammation 11:201

37. Lun MP, Monuki ES, Lehtinen MK (2015) Development and functions of the choroid plexus-cerebrospinal fluid system. Nat Rev Neurosci 16:445-457

38. Schwartz M, Shechter R (2010) Protective autoimmunity functions by intracranial immunosurveillance to support the mind: the missing link between health and disease. Mol Psychiatry 15: 342-354

39. Schwartz M, Raposo C (2014) Protective autoimmunity: a unifying model for the immune network involved in CNS repair. Neurosci Rev J Bringing Neurobiol Neurol Psychiatry 20:343358

40. Rezaie P, Male D (2002) Mesoglia \& microglia - a historical review of the concept of mononuclear phagocytes within the central nervous system. J Hist Neurosci 11:325-374

41. Ginhoux F, Prinz M (2015) Origin of microglia: current concepts and past controversies. Cold Spring Harb Perspect Biol 7:a020537

42. Hristovska I, Pascual O (2015) Deciphering resting microglial morphology and process motility from a synaptic prospect. Front Integr Neurosci 9:73

43. Correale $\mathrm{J}$ (2014) The role of microglial activation in disease progression. Mult Scler Houndmills Basingstoke Engl 20:1288-1295

44. Hernandez-Ontiveros DG, Tajiri N, Acosta S, Giunta B, Tan J, Borlongan CV (2013) Microglia activation as a biomarker for traumatic brain injury. Front Neurol 4:30

45. Ginhoux F, Lim S, Hoeffel G, Low D, Huber T (2013) Origin and differentiation of microglia. Front Cell Neurosci 7:45

46. Nayak D, Roth TL, McGavern DB (2014) Microglia development and function. Annu Rev Immunol 32:367-402

47. Wu Y, Dissing-Olesen L, MacVicar BA, Stevens B (2015) Microglia: dynamic mediators of synapse development and plasticity. Trends Immunol 36:605-613

48. Neumann H, Kotter MR, Franklin RJM (2009) Debris clearance by microglia: an essential link between degeneration and regeneration. Brain J Neurol 132:288-295

49. Bahrini I, Song J, Diez D, Hanayama R (2015) Neuronal exosomes facilitate synaptic pruning by up-regulating complement factors in microglia. Sci Rep 5:7989

50. Bátiz LF, Castro MA, Burgos PV, Velásquez ZD, Muñoz RI, Lafourcade CA et al (2015) Exosomes as novel regulators of adult neurogenic niches. Front Cell Neurosci 9:501

51. Pegtel DM, Peferoen L, Amor S (2014) Extracellular vesicles as modulators of cell-to-cell communication in the healthy and diseased brain. Philos Trans R Soc Lond B Biol Sci 369(1652)

52. Frühbeis C, Fröhlich D, Kuo WP, Amphornrat J, Thilemann S, Saab AS et al (2013) Neurotransmitter-triggered transfer of exosomes mediates oligodendrocyte-neuron communication. PLoS Biol 11:e1001604

53. Bellingham SA, Guo BB, Coleman BM, Hill AF (2012) Exosomes: vehicles for the transfer of toxic proteins associated with neurodegenerative diseases? Front Physiol 3:124

54. Turola E, Furlan R, Bianco F, Matteoli M, Verderio C (2012) Microglial microvesicle secretion and intercellular signaling. Front Physiol 3:149

55. Properzi F, Logozzi M, Fais S (2013) Exosomes: the future of biomarkers in medicine. Biomark Med 7:769-778

56. Wang X, Zhao L, Zhang J, Fariss RN, Ma W, Kretschmer F et al (2016) Requirement for microglia for the maintenance of synaptic function and integrity in the mature retina. J Neurosci 36:28272842 
57. Gertig U, Hanisch U-K (2014) Microglial diversity by responses and responders. Front Cell Neurosci 8:101

58. Wyss-Coray T, Rogers J (2012) Inflammation in Alzheimer disease - a brief review of the basic science and clinical literature. Cold Spring Harb Perspect Med 2:a006346

59. Streit WJ, Xue Q-S (2009) Life and death of microglia. J Neuroimmune Pharmacol Off J Soc NeuroImmune Pharmacol 4:371-379

60. Luo X-G, Chen S-D (2012) The changing phenotype of microglia from homeostasis to disease. Transl Neurodegener 1:9

61. von Bernhardi R, Eugenín-von Bernhardi L, Eugenín J (2015) Microglial cell dysregulation in brain aging and neurodegeneration. Front Aging Neurosci 7:124

62. Lynch MA (2014) The impact of neuroimmune changes on development of amyloid pathology; relevance to Alzheimer's disease. Immunology 141:292-301

63. Colton CA (2009) Heterogeneity of microglial activation in the innate immune response in the brain. J Neuroimmune Pharmacol Off J Soc NeuroImmune Pharmacol 4:399-418

64. Walker DG, Lue L-F (2015) Immune phenotypes of microglia in human neurodegenerative disease: challenges to detecting microglial polarization in human brains. Alzheimers Res Ther 7: 56

65. Cappellano G, Carecchio M, Fleetwood T, Magistrelli L, Cantello R, Dianzani U et al (2013) Immunity and inflammation in neurodegenerative diseases. Am J Neurodegener Dis 2:89-107

66. Heneka MT, Kummer MP, Latz E (2014) Innate immune activation in neurodegenerative disease. Nat Rev Immunol 14:463-477

67. Ferrini F, De Koninck Y (2013) Microglia control neuronal network excitability via BDNF signalling. Neural Plast 2013:429815

68. Alboni S, Maggi L (2015) Editorial: cytokines as players of neuronal plasticity and sensitivity to environment in healthy and pathological brain. Front Cell Neurosci 9:508

69. Sajja VSSS, Hlavac N, VandeVord PJ (2016) Role of glia in memory deficits following traumatic brain injury: biomarkers of glia dysfunction. Front Integr Neurosci 10:7

70. Camara ML, Corrigan F, Jaehne EJ, Jawahar MC, Anscomb H, Koerner $\mathrm{H}$ et al (2013) TNF- $\alpha$ and its receptors modulate complex behaviours and neurotrophins in transgenic mice. Psychoneuroendocrinology 38:3102-3114

71. Steinmetz CC, Turrigiano GG (2010) Tumor necrosis factor- $\alpha$ signaling maintains the ability of cortical synapses to express synaptic scaling. J Neurosci 30:14685-14690

72. Lull ME, Block ML (2010) Microglial activation and chronic neurodegeneration. Neurother J Am Soc Exp Neurother 7:354 365

73. Prinz M, Priller J (2014) Microglia and brain macrophages in the molecular age: from origin to neuropsychiatric disease. Nat Rev Neurosci 15:300-312

74. Block ML, Hong J-S (2007) Chronic microglial activation and progressive dopaminergic neurotoxicity. Biochem Soc Trans 35: $1127-1132$

75. Leszek J, Barreto GE, Gąsiorowski K, Koutsouraki E, ÁvilaRodrigues M, Aliev G (2016) Inflammatory mechanisms and oxidative stress as key factors responsible for progression of neurodegeneration: role of brain innate immune system. CNS Neurol Disord Drug Targets 15:329-336

76. Fischer R, Maier O (2015) Interrelation of oxidative stress and inflammation in neurodegenerative disease: role of TNF. Oxidative Med Cell Longev 2015:610813

77. Sochocka M, Koutsouraki ES, Gasiorowski K, Leszek J (2013) Vascular oxidative stress and mitochondrial failure in the pathobiology of Alzheimer's disease: a new approach to therapy. CNS Neurol Disord Drug Targets 12:870-881
78. Wu Z, Yu J, Zhu A, Nakanishi H (2016) Nutrients, microglia aging, and brain aging. Oxidative Med Cell Longev 2016: 7498528

79. Varnum MM, Ikezu T (2012) The classification of microglial activation phenotypes on neurodegeneration and regeneration in Alzheimer's disease brain. Arch Immunol Ther Exp 60:251-266

80. Yu Z, Sun D, Feng J, Tan W, Fang X, Zhao M et al (2015) MSX3 switches microglia polarization and protects from inflammationinduced demyelination. J Neurosci 35:6350-6365

81. Cherry JD, Olschowka JA, O'Banion MK (2014) Neuroinflammation and M2 microglia: the good, the bad, and the inflamed. J Neuroinflammation 11:98

82. Cerbai F, Lana D, Nosi D, Petkova-Kirova P, Zecchi S, Brothers $\mathrm{HM}$ et al (2012) The neuron-astrocyte-microglia triad in normal brain ageing and in a model of neuroinflammation in the rat hippocampus. PLoS One 7:e45250

83. McGeer PL, McGeer EG (2015) Targeting microglia for the treatment of Alzheimer's disease. Expert Opin Ther Targets 19:497506

84. Latta CH, Brothers HM, Wilcock DM (2015) Neuroinflammation in Alzheimer's disease; a source of heterogeneity and target for personalized therapy. Neuroscience 302:103-111

85. Moore CS, Rao VTS, Durafourt BA, Bedell BJ, Ludwin SK, BarOr A et al (2013) miR-155 as a multiple sclerosis-relevant regulator of myeloid cell polarization. Ann Neurol 74:709-720

86. Hamzei Taj S, Kho W, Riou A, Wiedermann D, Hoehn M (2016) MiRNA-124 induces neuroprotection and functional improvement after focal cerebral ischemia. Biomaterials 91:151-165

87. Ponomarev ED, Veremeyko T, Weiner HL (2013) MicroRNAs are universal regulators of differentiation, activation, and polarization of microglia and macrophages in normal and diseased CNS. Glia 61:91-103

88. Magistretti PJ, Ransom BR (2002) Astrocytes. Neuropsychopharmacology: the fifth generation of progress. In: Davis KL, Charney D, Coyle JT, NemeroffC (eds). Williams and Wilkins, Philadelphia, Lippincott, pp 133-145

89. Steardo L, Bronzuoli MR, Iacomino A, Esposito G, Steardo L, Scuderi C (2015) Does neuroinflammation turn on the flame in Alzheimer's disease? Focus on astrocytes. Front Neurosci 9:259

90. Messing A, Brenner M (2003) GFAP: functional implications gleaned from studies of genetically engineered mice. Glia 43: $87-90$

91. Tanaka KF, Takebayashi H, Yamazaki Y, Ono K, Naruse M, Iwasato T et al (2007) Murine model of Alexander disease: analysis of GFAP aggregate formation and its pathological significance. Glia 55:617-631

92. Mohn TC, Koob AO (2015) Adult astrogenesis and the etiology of cortical neurodegeneration. J Exp Neurosci 9(Suppl 2):25-34

93. Fuller S, Steele M, Münch G (2010) Activated astroglia during chronic inflammation in Alzheimer's disease - do they neglect their neurosupportive roles? Mutat Res 690:40-49

94. Zhao J, O'Connor T, Vassar R (2011) The contribution of activated astrocytes to $A \beta$ production: implications for Alzheimer's disease pathogenesis. J Neuroinflammation 8:150

95. Efremova L, Chovancova P, Adam M, Gutbier S, Schildknecht S, Leist M (2016) Switching from astrocytic neuroprotection to neurodegeneration by cytokine stimulation. Arch Toxicol Apr 6

96. Villegas-Llerena C, Phillips A, Garcia-Reitboeck P, Hardy J, Pocock JM (2016) Microglial genes regulating neuroinflammation in the progression of Alzheimer's disease. Curr Opin Neurobiol 36:74-81

97. Yoon S, Kim Y (2015) The role of immunity and neuroinflammation in genetic predisposition. Aims Genet 2:230-249

98. Salminen A, Ojala J, Suuronen T, Kaarniranta K, Kauppinen A (2008) Amyloid-beta oligomers set fire to inflammasomes and induce Alzheimer's pathology. J Cell Mol Med 12:2255-2262 
99. de Vasconcelos NM, Van Opdenbosch N, Lamkanfi M (2016) Inflammasomes as polyvalent cell death platforms. Cell Mol Life Sci CMLS 73:2335-2347

100. Liu L, Chan C (2014) The role of inflammasome in Alzheimer's disease. Ageing Res Rev 15:6-15

101. Tan M-S, Yu J-T, Jiang T, Zhu X-C, Tan L (2013) The NLRP3 inflammasome in Alzheimer's disease. Mol Neurobiol 48:875882

102. Heneka MT, Golenbock DT, Latz E (2015) Innate immunity in Alzheimer's disease. Nat Immunol 16:229-236

103. Cagnin A, Brooks DJ, Kennedy AM, Gunn RN, Myers R, Turkheimer FE et al (2001) In-vivo measurement of activated microglia in dementia. Lancet Lond Engl 358:461-467

104. Edison P, Archer HA, Gerhard A, Hinz R, Pavese N, Turkheimer FE et al (2008) Microglia, amyloid, and cognition in Alzheimer's disease: an [11C](R)PK11195-PET and [11C]PIB-PET study. Neurobiol Dis 32:412-419

105. Okello A, Edison P, Archer HA, Turkheimer FE, Kennedy J, Bullock R et al (2009) Microglial activation and amyloid deposition in mild cognitive impairment: a PET study. Neurology 72:5662

106. Crack PJ, Bray PJ (2007) Toll-like receptors in the brain and their potential roles in neuropathology. Immunol Cell Biol 85:476-480

107. Kawai T, Akira S (2010) The role of pattern-recognition receptors in innate immunity: update on toll-like receptors. Nat Immunol 11: 373-384

108. Doi Y, Mizuno T, Maki Y, Jin S, Mizoguchi H, Ikeyama M et al (2009) Microglia activated with the toll-like receptor 9 ligand CpG attenuate oligomeric amyloid-beta neurotoxicity in in vitro and in vivo models of Alzheimer's disease. Am J Pathol 175:21212132

109. Fassbender K, Walter S, Kühl S, Landmann R, Ishii K, Bertsch T et al (2004) The LPS receptor (CD14) links innate immunity with Alzheimer's disease. FASEB J Off Publ Fed Am Soc Exp Biol 18: 203-205

110. Kielian T (2006) Toll-like receptors in central nervous system glial inflammation and homeostasis. J Neurosci Res 83:711-730

111. Scholtzova H, Kascsak RJ, Bates KA, Boutajangout A, Kerr DJ, Meeker HC et al (2009) Induction of toll-like receptor 9 signaling as a method for ameliorating Alzheimer's disease-related pathology. J Neurosci 29:1846-1854

112. Liu S, Liu Y, Hao W, Wolf L, Kiliaan AJ, Penke B et al (2012) TLR2 is a primary receptor for Alzheimer's amyloid $\beta$ peptide to trigger neuroinflammatory activation. J Immunol 188:1098-1107

113. Perkins ND (2007) Integrating cell-signalling pathways with NFkappaB and IKK function. Nat Rev Mol Cell Biol 8:49-62

114. Vigneron A, Vousden KH (2010) p53, ROS and senescence in the control of aging. Aging 2:471-474

115. Lucin KM, O’Brien CE, Bieri G, Czirr E, Mosher KI, Abbey RJ et al (2013) Microglial beclin 1 regulates retromer trafficking and phagocytosis and is impaired in Alzheimer's disease. Neuron 79: 873-886

116. Jaeger PA, Pickford F, Sun C-H, Lucin KM, Masliah E, WyssCoray T (2010) Regulation of amyloid precursor protein processing by the Beclin 1 complex. PLoS One 5:e11102

117. Salminen A, Kaarniranta K, Kauppinen A, Ojala J, Haapasalo A, Soininen $\mathrm{H}$ et al (2013) Impaired autophagy and APP processing in Alzheimer's disease: the potential role of Beclin 1 interactome. Prog Neurobiol 106-107:33-54

118. Painter MM, Atagi Y, Liu C-C, Rademakers R, Xu H, Fryer JD et al (2015) TREM2 in CNS homeostasis and neurodegenerative disease. Mol Neurodegener 10:43

119. Boutajangout A, Wisniewski T (2013) The innate immune system in Alzheimer's disease. Int J Cell Biol 2013:576383
120. Wang Y, Cella M, Mallinson K, Ulrich JD, Young KL, Robinette ML et al (2015) TREM2 lipid sensing sustains the microglial response in an Alzheimer's disease model. Cell 160:1061-1071

121. Jiang T, Zhang Y-D, Chen Q, Gao Q, Zhu X-C, Zhou J-S et al (2016) TREM2 modifies microglial phenotype and provides neuroprotection in P301S tau transgenic mice. Neuropharmacology 105:196-206

122. Pottier C, Wallon D, Rousseau S, Rovelet-Lecrux A, Richard A-C, Rollin-Sillaire A et al (2013) TREM2 R47H variant as a risk factor for early-onset Alzheimer's disease. J Alzheimers Dis JAD 35:4549

123. Jonsson T, Stefansson H, Steinberg S, Jonsdottir I, Jonsson PV, Snaedal J et al (2013) Variant of TREM2 associated with the risk of Alzheimer's disease. N Engl J Med 368:107-116

124. Lill CM, Rengmark A, Pihlstrøm L, Fogh I, Shatunov A, Sleiman PM et al (2015) The role of TREM2 R47H as a risk factor for Alzheimer's disease, frontotemporal lobar degeneration, amyotrophic lateral sclerosis, and Parkinson's disease. Alzheimers Dement J Alzheimers Assoc 11:1407-1416

125. Rivest $\mathrm{S}$ (2015) TREM2 enables amyloid $\beta$ clearance by microglia. Cell Res 25:535-536

126. Ulrich JD, Holtzman DM (2016) TREM2 function in Alzheimer's disease and neurodegeneration. ACS Chem Neurosci 7:420-427

127. Colonna M, Wang Y (2016) TREM2 variants: new keys to decipher Alzheimer disease pathogenesis. Nat Rev Neurosci 17:201207

128. Hamelin L, Lagarde J, Dorothée G, Leroy C, Labit M, Comley RA et al (2016) Early and protective microglial activation in Alzheimer's disease: a prospective study using 18F-DPA-714 PET imaging. Brain J Neurol 139:1252-1264

129. Refolo V, Stefanowa N (2015) Microglia activation as a therapeutic target in multiple system atrophy: the timing, the good and the bad. Macrophage 2:e1065

130. Griffin WST, Mrak RE (2002) Interleukin-1 in the genesis and progression of and risk for development of neuronal degeneration in Alzheimer's disease. J Leukoc Biol 72:233-238

131. McNaull BBA, Todd S, McGuinness B, Passmore AP (2010) Inflammation and anti-inflammatory strategies for Alzheimer's disease - a mini-review. Gerontology 56:3-14

132. Rubio-Perez JM, Morillas-Ruiz JM (2012) A review: inflammatory process in Alzheimer's disease, role of cytokines. ScientificWorldJournal 2012:756357

133. McAfoose J, Baune BT (2009) Evidence for a cytokine model of cognitive function. Neurosci Biobehav Rev 33:355-366

134. Delaby C, Gabelle A, Blum D, Schraen-Maschke S, Moulinier A, Boulanghien J et al (2015) Central nervous system and peripheral inflammatory processes in Alzheimer's disease: biomarker profiling approach. Front Neurol 6:181

135. Zambrano A, Otth C, Maccioni RB, Concha II (2010) IL-3 controls tau modifications and protects cortical neurons from neurodegeneration. Curr Alzheimer Res 7:615-624

136. Zambrano A, Otth C, Mujica L, Concha II, Maccioni RB (2007) Interleukin-3 prevents neuronal death induced by amyloid peptide. BMC Neurosci 8:82

137. Natarajan C, Sriram S, Muthian G, Bright JJ (2004) Signaling through JAK2-STAT5 pathway is essential for IL-3-induced activation of microglia. Glia 45:188-196

138. Smith JA, Das A, Ray SK, Banik NL (2012) Role of proinflammatory cytokines released from microglia in neurodegenerative diseases. Brain Res Bull 87:10-20

139. Gordon S, Martinez FO (2010) Alternative activation of macrophages: mechanism and functions. Immunity 32:593-604

140. Latta CH, Sudduth TL, Weekman EM, Brothers HM, Abner EL, Popa GJ et al (2015) Determining the role of IL-4 induced neuroinflammation in microglial activity and amyloid- $\beta$ using BV2 
microglial cells and APP/PS1 transgenic mice. J Neuroinflammation 12:41

141. Liu C, Cui G, Zhu M, Kang X, Guo H (2014) Neuroinflammation in Alzheimer's disease: chemokines produced by astrocytes and chemokine receptors. Int J Clin Exp Pathol 7:8342-8355

142. Guillot-Sestier M-V, Doty KR, Gate D, Rodriguez J, Leung BP, Rezai-Zadeh K et al (2015) Il10 deficiency rebalances innate immunity to mitigate Alzheimer-like pathology. Neuron 85:534-548

143. Aloisi F, Penna G, Cerase J, Menéndez Iglesias B, Adorini L (1997) IL-12 production by central nervous system microglia is inhibited by astrocytes. J Immunol Baltim Md 1950 159:16041612

144. Vom Berg J, Prokop S, Miller KR, Obst J, Kälin RE, LopateguiCabezas I et al (2012) Inhibition of IL-12/IL-23 signaling reduces Alzheimer's disease-like pathology and cognitive decline. Nat Med 18:1812-1819

145. Bishnoi RJ, Palmer RF, Royall DR (2015) Serum interleukin (IL)15 as a biomarker of Alzheimer's disease. PLoS One 10:e117282

146. Rentzos M, Rombos A (2012) The role of IL-15 in central nervous system disorders. Acta Neurol Scand 125:77-82

147. Sutinen EM, Pirttilä T, Anderson G, Salminen A, Ojala JO (2012) Pro-inflammatory interleukin-18 increases Alzheimer's diseaseassociated amyloid- $\beta$ production in human neuron-like cells. J Neuroinflammation 9:199

148. Salani F, Ciaramella A, Bizzoni F, Assogna F, Caltagirone C, Spalletta G et al (2013) Increased expression of interleukin-18 receptor in blood cells of subjects with mild cognitive impairment and Alzheimer's disease. Cytokine 61:360-363

149. Yasuoka S, Kawanokuchi J, Parajuli B, Jin S, Doi Y, Noda M et al (2011) Production and functions of IL-33 in the central nervous system. Brain Res 1385:8-17

150. Gadani SP, Walsh JT, Lukens JR, Kipnis J (2015) Dealing with danger in the CNS: the response of the immune system to injury. Neuron 87:47-62

151. Zheng C, Zhou X-W, Wang J-Z (2016) The dual roles of cytokines in Alzheimer's disease: update on interleukins, TNF- $\alpha$, TGF- $\beta$ and IFN- $\gamma$. Transl Neurodegener 5:7

152. Sriram K, O’Callaghan JP (2007) Divergent roles for tumor necrosis factor-alpha in the brain. J Neuroimmune Pharmacol Off J Soc NeuroImmune Pharmacol 2:140-153

153. Rocha NP, Teixeira AL, Coelho FM, Caramelli P, Guimarães HC, Barbosa IG et al (2012) Peripheral blood mono-nuclear cells derived from Alzheimer's disease patients show elevated baseline levels of secreted cytokines but resist stimulation with $\beta$ amyloid peptide. Mol Cell Neurosci 49:77-84

154. Sastre M, Klockgether T, Heneka MT (2006) Contribution of inflammatory processes to Alzheimer's disease: molecular mechanisms. Int J Dev Neurosci Off J Int Soc Dev Neurosci 24:167-176

155. Hsieh H-L, Yang C-M (2013) Role of redox signaling in neuroinflammation and neurodegenerative diseases. Biomed Res Int 2013:484613

156. Fischer R, Maier O, Siegemund M, Wajant H, Scheurich $\mathrm{P}$, Pfizenmaier K (2011) A TNF receptor 2 selective agonist rescues human neurons from oxidative stress-induced cell death. PLoS One 6:e27621

157. Chiarini A, Dal Pra I, Whitfield JF, Armato U (2006) The killing of neurons by beta-amyloid peptides, prions, and proinflammatory cytokines. Ital J Anat Embryol Arch Ital Anat Ed Embriologia 111:221-246

158. Kempuraj D, Khan MM, Thangavel R, Xiong Z, Yang E, Zaheer A (2013) Glia maturation factor induces interleukin-33 release from astrocytes: implications for neurodegenerative diseases. $\mathrm{J}$ Neuroimmune Pharmacol Off J Soc NeuroImmune Pharmacol 8: 643-650

159. Ryu JK, Cho T, Choi HB, Jantaratnotai N, McLarnon JG (2015) Pharmacological antagonism of interleukin-8 receptor CXCR2 inhibits inflammatory reactivity and is neuroprotective in an animal model of Alzheimer's disease. J Neuroinflammation 12:144

160. Morrison RS, Kinoshita Y, Johnson MD, Guo W, Garden GA (2003) p53-dependent cell death signaling in neurons. Neurochem Res 28:15-27

161. Culmsee C, Mattson MP (2005) p53 in neuronal apoptosis. Biochem Biophys Res Commun 331:761-777

162. Chang JR, Ghafouri M, Mukerjee R, Bagashev A, Chabrashvili T, Sawaya BE (2012) Role of p53 in neurodegenerative diseases. Neurodegener Dis 9:68-80

163. Lanni C, Uberti D, Racchi M, Govoni S, Memo M (2007) Unfolded p53: a potential biomarker for Alzheimer's disease. J Alzheimers Dis JAD 12:93-99

164. Bartel DP (2004) MicroRNAs: genomics, biogenesis, mechanism, and function. Cell 116:281-297

165. Hermeking H (2012) MicroRNAs in the p53 network: micromanagement of tumour suppression. Nat Rev Cancer 12:613-626

166. Eun B, Cho B, Moon Y, Kim SY, Kim K, Kim H et al (2010) Induction of neuronal apoptosis by expression of Hes6 via p53dependent pathway. Brain Res 1313:1-8

167. Hooper C, Meimaridou E, Tavassoli M, Melino G, Lovestone S, Killick R (2007) p53 is upregulated in Alzheimer's disease and induces tau phosphorylation in HEK293a cells. Neurosci Lett 418: 34-37

168. Maddocks ODK, Vousden KH (2011) Metabolic regulation by p53. J Mol Med Berl Ger 89:237-245

169. Vousden KH (2010) Alternative fuel - another role for $\mathrm{p} 53$ in the regulation of metabolism. Proc Natl Acad Sci U S A 107:71177118

170. Cai D (2013) Neuroinflammation and neurodegeneration in overnutrition-induced diseases. Trends Endocrinol Metab TEM 24:40-47

171. Buizza L, Prandelli C, Bonini SA, Delbarba A, Cenini G, Lanni C et al (2013) Conformational altered p53 affects neuronal function: relevance for the response to toxic insult and growth-associated protein 43 expression. Cell Death Dis 4:e484

172. Stanga S, Lanni C, Govoni S, Uberti D, D’Orazi G, Racchi M (2010) Unfolded p53 in the pathogenesis of Alzheimer's disease: is HIPK2 the link? Aging 2:545-554

173. Bendotti C, Baldessari S, Pende M, Southgate T, Guglielmetti F, Samanin R (1997) Relationship between GAP-43 expression in the dentate gyrus and synaptic reorganization of hippocampal mossy fibres in rats treated with kainic acid. Eur J Neurosci 9: 93-101

174. Ambros V, Chen X (2007) The regulation of genes and genomes by small RNAs. Dev Camb Engl 134:1635-1641

175. Leung AKL, Sharp PA (2010) MicroRNA functions in stress responses. Mol Cell 40:205-215

176. Mendell JT, Olson EN (2012) MicroRNAs in stress signaling and human disease. Cell 148:1172-1187

177. Holcik M, Sonenberg N (2005) Translational control in stress and apoptosis. Nat Rev Mol Cell Biol 6:318-327

178. Vojta A, Zoldoš V (2013) Adaptation or malignant transformation: the two faces of epigenetically mediated response to stress. Biomed Res Int 2013:954060

179. Vaseva AV, Marchenko ND, Ji K, Tsirka SE, Holzmann S, Moll UM (2012) p53 opens the mitochondrial permeability transition pore to trigger necrosis. Cell 149:1536-1548

180. Suzuki HI, Yamagata K, Sugimoto K, Iwamoto T, Kato S, Miyazono K (2009) Modulation of microRNA processing by p53. Nature 460:529-533

181. Suzuki HI, Miyazono K (2010) Dynamics of microRNA biogenesis: crosstalk between p53 network and microRNA processing pathway. J Mol Med Berl Ger 88:1085-1094 